\title{
PMFF: Development of a Physics-Based Molecular Force Field for Protein Simulation and Ligand Docking
}

Sung Bo Hwang, Chang Joon Lee, Sehan Lee, Songling Ma, Young-Mook Kang, Kwang Hwi Cho, Su-Yeon Kim, Oh Young Kwon, Chang No Yoon, Young Kee Kang, Jeong Hyeok Yoon, Ky-Youb Nam, Seong-Gon Kim, Youngyong In, Han Ha Chai, William E. Acree, Jr., J. Andrew Grant, Ken D. Gibson, Mu Shik Jhon, Harold A. Scheraga, and Kyoung Tai No*

Cite This: J. Phys. Chem. B 2020, 124, 974-989

ABSTRACT: The physics-based molecular force field (PMFF) was developed by integrating a set of potential energy functions in which each term in an intermolecular potential energy function is derived based on experimental values, such as the dipole moments, lattice energy, proton transfer energy, and X-ray crystal structures. The term "physics-based" is used to emphasize the idea that the experimental observables that are considered to be the most relevant to each term are used for the parameterization rather than parameterizing all observables together against the target value. PMFF uses MM3 intramolecular potential energy terms to describe intramolecular interactions and includes an implicit solvation model specifically developed for the PMFF. We evaluated the PMFF in three ways. We concluded that the PMFF provides reliable information based on the structure in a biological system and interprets the biological phenomena accurately by providing more accurate evidence of the biological phenomena.

\section{INTRODUCTION}

Because the biological activities of biomolecules depend on their molecular structures, it is necessary to obtain the correct threedimensional structure of the target biomolecule to describe its physical, chemical, and biological properties. Over the past several decades, the three-dimensional structures of many biomolecules, such as protein, DNA, RNA, and their complexes, have been identified through X-ray or NMR experiments, and their number is growing rapidly. As the number of biomolecular structures and the demand for computational structural biology increase, particularly in the field of drug discovery, it is necessary to describe and predict the function of biomolecules using computational methods, such as a molecular docking simulation and molecular dynamics simulation.

The computational methods for biomolecules are composed of two main parts: a simulation algorithm that can accurately simulate natural phenomena or processes, and energy calculation methods for the system to be investigated. The energy calculation method can be roughly divided into two classes: a quantum-mechanics based molecular orbital (MO) calculation and a molecular-mechanics based empirical potential energy function called a force field. Although MO calculation methods provide more accurate results for the structure and intermolecular interactions of the target molecules, a high computational cost hinders their application to large systems, such as biomolecules. The time required for a Hartree-Fock calculation, which is a representative $\mathrm{MO}$ calculation, increases by approximately $n^{4}$ where $n$ corresponds to the number of basis functions. However, the time required in a force field is proportional to slightly more than $\mathrm{m}^{4}$ where $m$ corresponds to the number of atoms. Therefore, a force field is more proper for application to large biomolecules and is frequently considered to be used to study not only the static but also dynamic properties of biomolecules.

A force field consists of equations and parameters that define the potential energy surface of a molecule. The potential energy used in a force field is composed of intramolecular and intermolecular energy components. In general, the parameters are not transferable from one force field to another because they are correlated within the force field. The reliability of the force field was dependent on several factors, such as mathematical equations for each component, the optimum set of parameters, and molecules included in the parameterization process.

Several force fields that are broadly used include the Empirical Conformational Energy Program for Peptides (ECEPP), ${ }^{1-5}$ a Molecular Mechanics (MM) force field, ${ }^{6-8}$ Chemistry at

Received: November 4, 2019

Revised: January 11, 2020

Published: January 15, 2020 
Harvard Molecular Mechanics (CHARMM), ${ }^{9-17}$ Assisted Model Building with Energy Refinement (AMBER), ${ }^{18-23}$ Merck Molecular Force Field (MMFF), ${ }^{24-28}$ Consistent Valence Force Field (CVFF), ${ }^{29}$ and Optimized Potentials for Liquid Simulations (OPLS). ${ }^{30-32}$ ECEPP was developed to calculate the interatomic interactions between amino acid residues to delineate the conformational energy of polypeptides and proteins. ${ }^{5}$ ECEPP consists of electrostatic, nonbonded, hydrogen bond, and torsional terms in its potential energy function (PEF). This energy configuration is advantageous in a Monte Carlo simulation focused on the torsional space but disadvantageous in a molecular dynamics simulation owing to the absence of a PEF to describe the bond stretching and angle bending in molecular dynamics. MM3, the third version of MM, was developed with accurate intramolecular potential functions to allow a precise energy difference in the conformational change of small molecules to be calculated. In particular, the MM3 electrostatic potential energy is calculated by charge distribution represented by a set of bond dipoles. For electrostatic potential energy calculation, MM3 introduced the charge-charge and charge-dipole interactions together. CHARMM is extensively used to simulate the properties of proteins, nucleic acids, lipids, and carbohydrates. To use for drug-like molecules, CHARMM General Force Field (CGenFF) ${ }^{10}$ was developed in 2009. Potential parameters used in CGenFF newly introduced for heterocyclic scaffolds and the atoms those attached to the hetero cyclic scaffold. Therefore, CGenFF is better suited for drug design studies than original CHARMM. AMBER is mainly focused on biomolecules such as proteins and nucleic acid. Charges, called an electrostatic potential (ESP) charge, fit the quantum electrostatic potential energy from a quantum chemistry calculation at the HF $6-31 G^{*}$ level. The van der Waals parameters were derived from amide crystal data by Lifson's group ${ }^{33,34}$ and from liquid-state simulations calculated by Jorgensen. ${ }^{35}$ Force constants, bond lengths, and bond angles were derived from the crystal structure and adapted to match the normal-mode frequencies for peptide fragments. MMFF was developed for pharmaceutical applications and calculates not only in the gas phase but also in the condensed phase. ${ }^{24}$ The potential parameters of MMFF were obtained by using the energy and electrostatic properties as constraints, and the reliability of the parameters was verified by comparing with experimental data. The type of data used to develop the MMFF is a receptor-ligand interaction involving proteins and nucleic acids as a receptor and a large assortment of chemical structures and ligands. The CVFF is focused on the simulation of organic, polymeric, and biopolymeric systems, as well as the modeling of vibrational spectroscopic properties. The CVFF parameters are derived from the energy and its first and second derivatives with respect to the coordinates of the amino acids, water, and a variety of other functional groups. OPLS consists of intramolecular PEFs in AMBER and intermolecular PEFs developed by Jorgensen's group. This force field is focused on the modeling of a liquid-phase system, whereas the other force fields are focused on the gas-phase system. To represent a liquid system accurately, the training set used in the OPLS parameterization consists of liquid-phase data instead of gas-phase data and molecular structures are calculated through a Monte Carlo simulation to represent a liquid. Each force field has a slightly different functional form, parameters, and experimental dataset used during the parametrization process to serve the developer's purpose. Because no force fields are quite applicable to all cases, most are still used in different places to meet different needs.
Owing to the aqueous environment in a biological system, it is important to include a reliable solvation model that describes solute-solvent and solvent-solvent interactions directly and a solute-solute interaction indirectly. In addition, it is ideal to have a solvation model that harmonizes well with other intermolecular energy components. In the case of CHARMM, AMBER, and OPLS, their parameters were optimized for the TIP3P water model, an explicit solvation model. ${ }^{30}$ Since in explicit solvation models, the positions and interactions of the atoms of the water molecules are explicitly treated, the number of the atoms in a simulation biological system is considerably large, and the simulation takes an extremely long time to obtain reasonable results. To overcome these limitations, many implicit models ${ }^{36-40}$ have been developed. In implicit models, some of the force field parameters were modified in order to include the influence of the interaction between biological molecules and water.

Herein, we introduce a new type of force field called a physicsbased molecular force field (PMFF) that consists of MM3 intramolecular potential energy functions, a newly developed intermolecular energy component comparable to an MM3 force field, and an implicit solvation model. The solvation model was developed based on the parameters used in intermolecular interactions of this force field for harmonization between the solvation model and other intermolecular energy components. Because the solvation model is an implicit model, it requires a lower computational cost than other explicit solvation models. We call this new force field a physics-based molecular force field to emphasize that all parameters in each term in the intermolecular potential energy functions are derived based on experimental values, such as dipole moments, lattice energy, proton transfer energy, and X-ray crystal structures, and it calculates reliable energy with fewer parameters using physicsbased theory. Details are well described in Section 2.2.

The reliability and suitability among the energy components in a PMFF were examined using the conformer energy difference of certain organic compounds, a molecular docking simulation, and the octanol-water partition coefficient of the peptides.

\section{METHOD}

A force field calculates the potential energy, $V_{\text {Total }}$, by summing the intra- and intermolecular potential energies and the solvation free energy as follows:

$$
V_{\text {Total }}=V_{\text {Intra }}+V_{\text {Inter }}+V_{\text {solv }}
$$

where $V_{\text {Intra }}$ and $V_{\text {Inter }}$ represent the intra- and intermolecular potential energy, respectively, and $V_{\text {solv }}$ represents the solvationfree energy of a system.

It was assumed that the intra-atomic potential functions are not significantly affected by the interatomic interactions, and thus we considered the potential parameters of stretching, bending, and torsional motions to be usable as is without any modifications even if the chemical environments, mainly through space interactions, change. Based on this assumption, a PMFF potential set introduced in the MM3 intramolecular $\mathrm{PEF}$ for $V_{\text {Intra }}$; an intermolecular PEF, that is, $V_{\text {Inter }}$ and a solvation-free energy, that is, $V_{\text {solv }}$, calculation model was newly developed.

2.1. Intramolecular Potential Energy Function. The MM3 intramolecular potential function parameter set was introduced for the intramolecular potential energy calculation of the PMFF set because the MM3 calculates the intramolecular potential energy in the most precise manner through an 


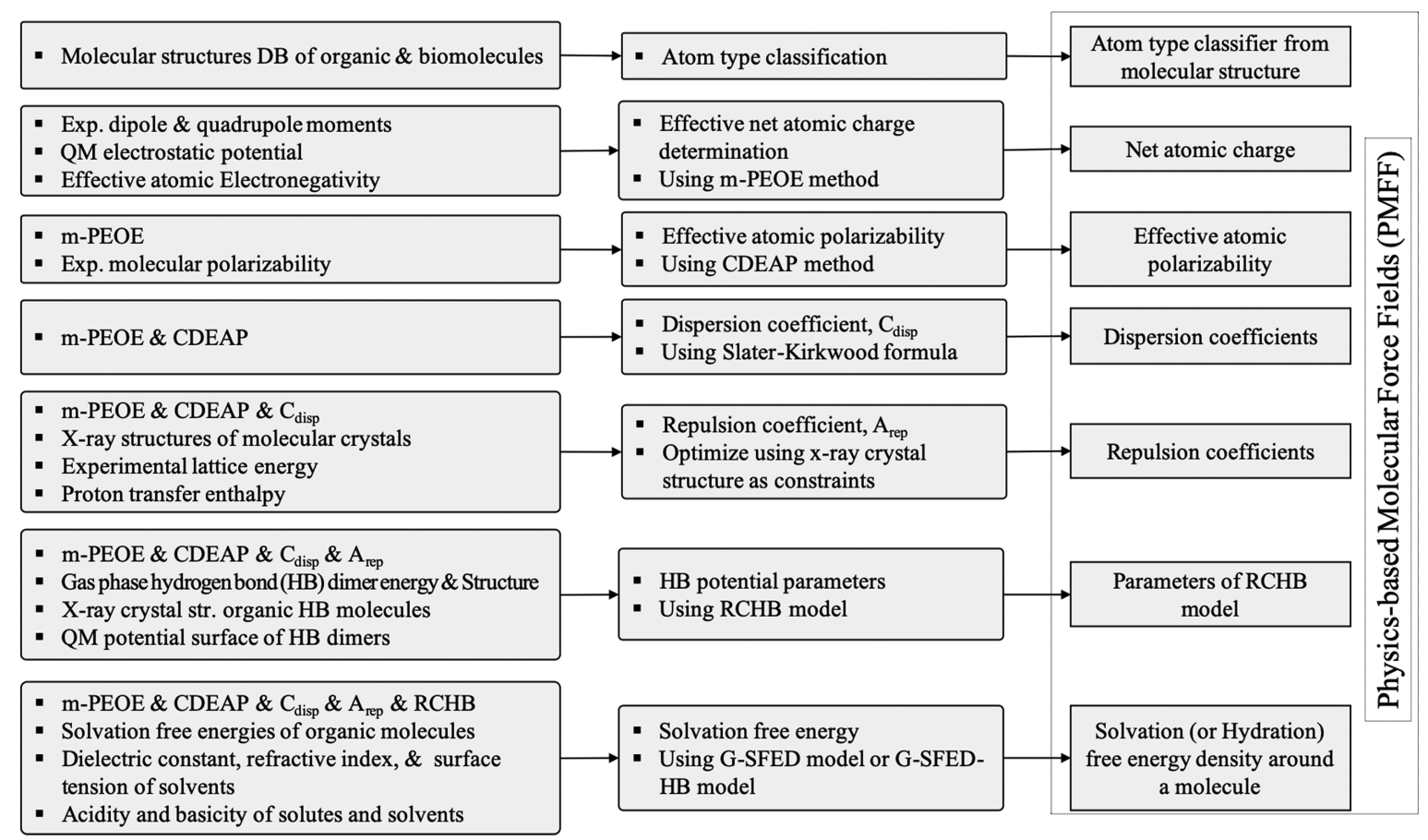

Figure 1. Sequential process of the intermolecular potential energy function set development in PMFF. The components of intermolecular potential energy function set were dependent on other components of the intermolecular potential energy function. Effective atomic polarizability is dependent on the net atomic charge. The nonbonding potential energy function is developed by parameters determined by atomic partial charge and atomic polarizability. The hydrogen bond potential energy function is developed by parameters determined by net atomic charge and nonbonding parameters. The solvation free energy function is developed by parameters determined by net atomic charge, atomic polarizability, nonbonding parameter, and hydrogen bond parameters.

introduction of an energy term accounting for couplings between internal coordinates. ${ }^{6}$ The MM3 intramolecular potential function parameter set is described as follows:

$$
\begin{aligned}
V_{\text {Intra }}= & V_{\text {stretch }}+V_{\text {bend }}+V_{\text {Torsion }}+V_{\text {Cross }}+V_{\text {intra-electrostatic }} \\
& +V_{\text {intra-vdW }}
\end{aligned}
$$

where $V_{\text {Intra }}$ is the intramolecular potential energy, $V_{\text {stretch }}$ is the bond stretch potential energy, $V_{\text {bend }}$ is the angle bending potential energy, $V_{\text {Torsion }}$ is the torsional potential energy, $V_{\text {Cross }}$ is the energy of the cross terms among the intra coordinates, $V_{\text {intra-electrostatic }}$ is the intramolecular electrostatic potential energy, and $V_{\text {intra }}$ vdW is the intramolecular van der Waals $(\mathrm{vdW})$ potential energy. The role of the cross term is to act as a coupling effect between two components of the intramolecular potential energy and thus to represent the molecular structure more accurately. The cross term is described as follows:

$$
V_{\text {Cross }}=V_{\text {Stretch-Bend }}+V_{\text {Stretch-Torsion }}+V_{\text {Bend-Bend }}
$$

where $V_{\text {Stretch - Bend }}$ is the stretch-bending potential energy, $V_{\text {Stretch-Torsion }}$ is the stretch-torsion potential energy, and $V_{\text {Bend-Bend }}$ is the bending-bending potential energy. An atom set related to more than 1-4 topological distances was calculated using $V_{\text {intra - electrostatic }}$ and $V_{\text {intra }-\mathrm{vdW}}$. The function

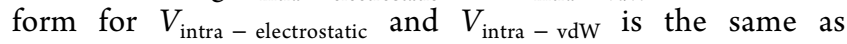
intermolecular electrostatic and $\mathrm{vdW} \mathrm{PEF}$, and a detailed description is given in the following section.

2.2. Intermolecular Potential Energy Function. The intermolecular PEFs of a PMFF can be described as follows:

$$
V_{\text {Inter }}=V_{\text {Electrostatic }}+V_{\text {pol }}+V_{\mathrm{vdW}}+V_{\mathrm{H}-\text { Bond }}
$$

where $V_{\text {Inter }}$ is the intermolecular potential energy, $V_{\text {Electrostatic }}$ is the electrostatic potential energy, $V_{\text {pol }}$ is the polarization potential energy, $V_{\mathrm{vdW}}$ is the vdW potential energy, and $V_{\mathrm{H}}$ - Bond is the potential energy of a hydrogen bond (HB).

The sequential process of the intermolecular PEF parameter set development is illustrated in Figure 1. The potential parameters of the components of eq 4 were determined based on a modified partial equalization of an orbital electronegativity $(\mathrm{m}-\mathrm{PEOE})^{41-45}$ model determined through experimental dipole and quadrupole moments and the quantum mechanical electrostatic potential energy. An electrostatic PEF is calculated using the effective net atomic charges on the atoms in the molecule or molecules. The other potential parameters are determined sequentially and self-consistently. vdW PEF is calculated using the dispersion parameters determined using the Slater-Kirkwood formula ${ }^{46}$ and charge dependence of the effective atomic polarizability (CDEAP) model, ${ }^{47}$ as well as the repulsion parameters determined based on the $\mathrm{X}$-ray structures of molecular crystals, the experimental lattice energy, and proton transfer enthalpy. ${ }^{48}$ A hydrogen-bond PEF is calculated using parameters determined by the gas-phase HB dimer energy and structure, X-ray crystal structure of organic hydrogen bond molecules, and the quantum mechanical potential surface of the HB dimer. ${ }^{49}$ Finally, the solvation-free energy function is calculated using a parameter determined through the experimental solvation-free energy of organic molecules as well as the peptides and various chemical properties. ${ }^{50,51}$

Because each intermolecular PEF in the PMFF is dependent on the other PEFs, the error is distributed evenly among the potential energy components, and trying to obtain the potential parameters results in a good balance among the components through the procedure we introduced for the parameter 
calculation and optimization in $V_{\text {Inter }}$. When developing the repulsion parameter used in vdW PEF, the X-ray crystal structure was optimized using electrostatic PEF. The parameters used in HB PEF were determined using electrostatic and vdW PEF. Therefore, intermolecular PEFs are harmonized. The potential set developed this time do not include $V_{\text {pol }}$ because calculation cost is expensive.

2.2.1. Effective Atomic Charge Calculation. In the PMFF, an atom-centered effective atomic point charge was used for the electrostatic potential energy calculation, and the effective atomic charges were calculated using a modified-PEOE (mPEOE) method. ${ }^{41-45}$ The electron flow between covalently bonded atoms $\mathrm{A}$ and $\mathrm{B}$ is calculated based on the electronegativity difference between atoms $\mathrm{A}$ and $\mathrm{B}$. Because the electron flow between covalently bonded atoms depends on the difference in the electronegativity of the atomic orbitals that participate in the chemical bond, a number of damping factors describing the different possible bond types in a biomolecule were introduced. The bond types and damping factors ${ }^{41-45}$ are summarized in Table 1. With the m-PEOE method, the electron

Table 1. Classification of Damping Factor Values According to Bond Type Used in Eq $5^{41-45, a}$

\begin{tabular}{|c|c|c|}
\hline $\begin{array}{l}\text { damping } \\
\text { factor }\end{array}$ & $\begin{array}{l}\text { parameter } \\
\text { value }\end{array}$ & bond type \\
\hline $\mathrm{fl}$ & 0.482 & $\mathrm{H}-\mathrm{sp}^{3}$ \\
\hline $\mathrm{f} 2$ & 0.569 & $\mathrm{H}-\mathrm{sp}^{2}$ \\
\hline $\mathrm{f} 3$ & 0.501 & $\mathrm{sp}^{3}-\mathrm{sp}^{3}$ \\
\hline $\mathrm{f} 4$ & 0.530 & $\mathrm{sp}^{3}-\mathrm{sp}^{2}$ \\
\hline f5 & 0.972 & $\mathrm{sp}^{2}-\mathrm{sp}^{2}$ \\
\hline f6 & 0.467 & $\mathrm{~N}^{+}-\mathrm{H}(\mathrm{N})$ \\
\hline f7 & 0.703 & $\mathrm{~N}^{+}-\mathrm{C}_{\text {alpha }}$ or $\mathrm{N}^{+}-\mathrm{C}\left(\mathrm{N}^{+}\right)$ \\
\hline f8 & 0.466 & $\mathrm{O}-\mathrm{C}\left(\mathrm{O}^{-}\right)$ \\
\hline f9 & 0.683 & $\mathrm{C}\left(\mathrm{O}^{-}\right)-\mathrm{C}_{\text {alpha }}$ \\
\hline $\mathrm{f} 10$ & 0.805 & $\mathrm{C}\left(\mathrm{O}^{-}\right)-\mathrm{C}\left(\mathrm{CO}_{2}^{-}\right)$ \\
\hline f11 & 0.441 & aromatic-aromatic $($ not $\mathrm{H})$ \\
\hline $\mathrm{f} 12$ & 0.549 & aromatic $-\mathrm{H}$ \\
\hline $\mathrm{f} 13$ & 0.664 & aromatic-not aromatic \\
\hline f14 & 0.699 & $\begin{array}{l}\mathrm{X}-\mathrm{C}, \mathrm{X}-\mathrm{N}, \mathrm{X}-\mathrm{O}, \mathrm{K}-\mathrm{C}, \mathrm{K}-\mathrm{N}, \mathrm{K}-\mathrm{O} \text {, nitro } \mathrm{O}-\mathrm{N} \\
\quad \text { (only neutal) }\end{array}$ \\
\hline f15 & 0.731 & $\mathrm{X}-\mathrm{C}, \mathrm{X}-\mathrm{N}, \mathrm{X}-\mathrm{O}$ (only charged) \\
\hline f16 & 0.501 & $\mathrm{Si}-\mathrm{H}$ \\
\hline $\mathrm{f} 17$ & 0.457 & $\mathrm{Si}-\mathrm{sp}^{3}$ \\
\hline f18 & 0.990 & $\mathrm{sp}-\mathrm{sp}$ \\
\hline f19 & 0.980 & $\mathrm{sp}-\mathrm{sp}^{2}$ \\
\hline $\mathrm{f} 20$ & 0.554 & $\mathrm{sp}-\mathrm{sp}^{3}$ \\
\hline $\mathrm{f} 21$ & 0.210 & $\mathrm{sp}-\mathrm{H}$ \\
\hline
\end{tabular}

${ }^{a}$ Damping factor was defined by the type of chemical bond to show nature of the electron distribution in different chemical bonds.

flow between the covalently bonded atoms A and B is calculated as follows: ${ }^{41-45}$

$$
d q_{\mathrm{AB}}^{\langle n\rangle}=\frac{\left[\chi_{\mathrm{B}}^{\langle n-1\rangle}-\chi_{\mathrm{A}}^{\langle n-1\rangle}\right]}{\chi_{\mathrm{A}^{+}}}\left(f_{\mathrm{AB}}\right)^{n} \operatorname{if}\left(\chi_{\mathrm{B}}^{\langle n-1\rangle}>\chi_{\mathrm{A}}^{\langle n-1\rangle}\right)
$$

where $d q_{\mathrm{AB}}^{\langle n\rangle}$ is the amount of electron flow between atoms $\mathrm{A}$ and $\mathrm{B}$ at the $n$th iteration, $\chi_{\mathrm{A}}^{\langle n-1\rangle}$ and $\chi_{\mathrm{B}}^{\langle n-1\rangle}$ are the electronegativity of atoms $\mathrm{A}$ and $\mathrm{B}$ at the $(n-1)$ th iteration, $\chi_{\mathrm{A}^{+}}$is the electronegativity of the positive ions of atom $\mathrm{A}$, and $f_{\mathrm{AB}}$ is the damping factor of bond type $\mathrm{A}-\mathrm{B}$. The electronegativity of atom A at the $n$th iteration, $\chi_{\mathrm{A}}^{\langle n\rangle}$, was recalculated as follows:

$$
\chi_{\mathrm{A}}^{\langle n\rangle}=a_{\mathrm{A}}+b_{\mathrm{A}} Q_{\mathrm{A}}^{\langle n\rangle}
$$

where $a_{i}$ and $b_{i}$ are m-PEOE coefficients (Table 2) and $Q_{A}^{\langle n\rangle}$ is the net atomic charge of atom $\mathrm{A}$ at the $n$th iteration, which is calculated as

$$
Q_{\mathrm{A}}^{\langle n\rangle}=Q_{\mathrm{A}}^{\langle 0\rangle}+\sum_{n} \sum_{\mathrm{B}} d q_{\mathrm{AB}}^{\langle n\rangle}
$$

where $Q_{A}^{\langle n\rangle}$ is the net atomic charge on atom $A$ after the $n$th iteration and $Q_{A}^{\langle 0\rangle}$ is the initial net atomic charge at atom $A$. The final atomic partial charges were obtained after the net atomic charges are converged through the iterative procedure.

2.2.2. Calculation of Effective Atomic Polarizabilities in a Molecule. The effective atomic polarizability concept is useful for calculating the molecular polarizability from the effective atomic polarizabilities using the additivity approximation, allowing the polarization stabilization energy under an atomatom pair potential approximation, as well as the dispersion interaction coefficients, to be calculated. The optimum effective atomic polarizabilities of the atoms in different hybrid states were determined by Miller and Savchik ${ }^{52}$ and Kang and Jhon. ${ }^{53}$ No et al. developed an effective atomic polarizability calculation method by considering the chemical environments of the atoms in a molecule, namely, the CDEAP model. ${ }^{47}$ With the CDEAP model, the effective atomic polarizability is described as a linear function of the net atomic charge as follows:

$$
\alpha_{\mathrm{A}}^{*}=\alpha_{\mathrm{A}, 0}^{*}-a_{\mathrm{A}} d q_{\mathrm{A}}
$$

where $\alpha_{\mathrm{A}}^{*}$ is the atomic polarizability at atom $\mathrm{A}, \alpha_{\mathrm{A}, 0}^{*}$ is the atomic polarizability at a zero effective net atomic charge of atom $A$, and $d q_{\mathrm{A}}$ is the net atomic charge calculated using $\mathrm{m}-\mathrm{PEOE}$ at the formal charged atom $\mathrm{A}$. The CDEAP parameters, $\alpha_{\mathrm{A}, 0}^{*}$ and $a_{\mathrm{A}}$, are described in Table 3.

2.2.3. van der Waals Potential Energy Function. For a nonbonding potential energy calculation, ${ }^{48}$ a Lennard-Jones potential function was introduced:

$$
\begin{aligned}
& V_{\mathrm{vdW}}=\sum_{i>j}\left(\frac{A_{i j}}{r_{i j}{ }^{12}}-\frac{C_{i j}}{r_{i j}{ }^{6}}\right)=\sum_{i>j} 4 \varepsilon_{i j}\left[\left(\frac{\sigma_{i j}}{r_{i j}}\right)^{12}-\left(\frac{\sigma_{i j}}{r_{i j}}\right)^{6}\right] \\
& \epsilon_{i j}=0.25 C_{i j}^{2} / A_{i j}, \sigma_{i j}=\left(\frac{A_{i j}}{C_{i j}}\right)^{1 / 6}
\end{aligned}
$$

where $r_{i j}$ is the distance between atoms $i$ and $j$ and $A_{i j}, C_{i j}, \varepsilon_{i j}$, and $\sigma_{i j}$ are Lennard-Jones potential parameters between atoms $i$ and $j$. These parameters for a heteroatomic pair were obtained using the following combination rule: ${ }^{54}$

$$
\begin{aligned}
& \varepsilon_{i j}=\left(\varepsilon_{i j} \varepsilon_{i j}\right)^{1 / 2} \\
& \sigma_{i j}=\left(\sigma_{i j}+\sigma_{i j}\right) / 2
\end{aligned}
$$

The Lennard-Jones potential parameters, $\varepsilon_{i i}$ and $\sigma_{i i}$ are summarized in Table 4.

2.2.4. Angle-Dependent HB Potential Energy Function. A simple hydrogen bond model was proposed by No et al. ${ }^{49}$ where the $1-3$ atomic pairs in a hydrogen-bonded system proved to be the most important terms in the description of the angular dependence of the hydrogen bond potential surfaces. To describe the angle dependency of such a surface, an interatomic distance set $\left(r_{\mathrm{HA}}, r_{\mathrm{XA}}, r_{\mathrm{BH}}\right.$, and $\left.r_{\mathrm{XB}}\right)$, described in Figure $2 \mathrm{~b}$, was 
Table 2. Electronegativity Parameter Set According to Atom Type Used in Eqs 7 and $8^{41-45, a}$

\begin{tabular}{|c|c|c|c|c|}
\hline atom & atom type & $a_{i}$ & $b_{i}$ & $Q_{i}^{\langle 0\rangle}$ \\
\hline $\mathrm{C}$ & $\mathrm{Csp}^{2}$ & 9.795 & 25.195 & 0.00 \\
\hline $\mathrm{C}$ & Car & 9.288 & 7.919 & 0.00 \\
\hline $\mathrm{C}$ & $\mathrm{Csp}^{3}$ & 7.967 & 4.862 & 0.00 \\
\hline $\mathrm{C}$ & $\mathrm{C}=\mathrm{O}$ & 8.218 & 8.288 & 0.00 \\
\hline $\mathrm{C}$ & $\mathrm{Csp}^{3}-\mathrm{P} 5$ or $\mathrm{S} 6$ & 12.397 & 6.667 & 0.00 \\
\hline $\mathrm{C}$ & $\mathrm{Csp}^{3}-\mathrm{Si}$ & 7.767 & 12.429 & 0.00 \\
\hline $\mathrm{C}$ & Csp & 10.000 & 5.000 & 0.00 \\
\hline $\mathrm{C}$ & $\mathrm{Csp}^{3}-\mathrm{S} 4$ & 9.292 & 3.764 & 0.00 \\
\hline $\mathrm{C}$ & $\mathrm{C}-\mathrm{N}^{+}$ & 8.660 & 6.893 & 0.35 \\
\hline $\mathrm{C}$ & $\mathrm{CO}_{2}^{-}$ & 5.159 & 3.005 & 0.20 \\
\hline $\mathrm{C}$ & $\mathrm{C} \alpha$ & 7.772 & 2.008 & 0.35 \\
\hline $\mathrm{C}$ & $\mathrm{Csp}^{3}-\mathrm{P5}^{-}$or $\mathrm{S}^{-}$ & 14.384 & 7.411 & 0.20 \\
\hline $\mathrm{H}$ & $\mathrm{H}$ atom & 7.711 & 31.958 & 0.00 \\
\hline $\mathrm{H}$ & Har & 7.428 & 6.722 & 0.00 \\
\hline $\mathrm{H}$ & $\mathrm{H}-\mathrm{Si}$ & 9.097 & 3.727 & 0.00 \\
\hline $\mathrm{H}$ & $\mathrm{H}-\mathrm{Csp}$ & 7.780 & 20.000 & 0.00 \\
\hline $\mathrm{H}$ & $\mathrm{H}-\mathrm{N}^{+}$ & 7.067 & 8.445 & 0.35 \\
\hline $\mathrm{H}$ & $\mathrm{H}-\mathrm{C} \alpha$ & 9.024 & 9.962 & 0.05 \\
\hline $\mathrm{H}$ & $\mathrm{H}-\mathrm{CO}_{2}^{-}$ & 7.963 & 19.067 & 0.10 \\
\hline $\mathrm{O}$ & Oar & 10.896 & 11.136 & 0.00 \\
\hline $\mathrm{O}$ & Osp ${ }^{2}$ & 14.284 & 13.857 & 0.00 \\
\hline $\mathrm{O}$ & Osp ${ }^{3}$ & 12.941 & 12.808 & 0.00 \\
\hline $\mathrm{O}$ & $\mathrm{Osp}^{3}-\mathrm{P} 5$ or $\mathrm{S} 6$ & 13.685 & 12.446 & 0.00 \\
\hline $\mathrm{O}$ & $\mathrm{Osp}^{2}=\mathrm{P} 5$ or $\mathrm{S} 6$ & 15.409 & 12.341 & 0.00 \\
\hline $\mathrm{O}$ & $\mathrm{Osp} \mathrm{p}^{3}-\mathrm{Si}$ & 7.767 & 12.429 & 0.00 \\
\hline $\mathrm{O}$ & $\mathrm{Osp}^{2}=\mathrm{S} 4$ & 14.495 & 13.039 & 0.00 \\
\hline $\mathrm{O}$ & $O s p^{3}-S 4$ & 13.062 & 10.860 & 0.00 \\
\hline $\mathrm{O}$ & $\mathrm{O}=\mathrm{C}-\mathrm{O}^{-}$ & 14.664 & 9.324 & -0.60 \\
\hline $\mathrm{O}$ & Osp ${ }^{3}-\mathrm{P} 5$ or $\mathrm{S} 6$ & 17.692 & 6.478 & -0.60 \\
\hline $\mathrm{O}$ & $\mathrm{O}-\mathrm{N}^{+}=\mathrm{O}$ & 16.263 & 13.130 & 0.00 \\
\hline $\mathrm{N}$ & Nar2 & 15.130 & 3.155 & 0.00 \\
\hline $\mathrm{N}$ & Nar3 & 12.941 & 3.240 & 0.00 \\
\hline $\mathrm{N}$ & $\mathrm{N}^{-}=$ & 15.478 & 11.914 & 0.00 \\
\hline $\mathrm{N}$ & $\mathrm{Nsp}^{3}$ & 12.184 & 13.538 & 0.00 \\
\hline $\mathrm{N}$ & $\mathrm{Nsp}^{3}-\mathrm{P} 5$ or $\mathrm{S} 6$ & 14.385 & 8.896 & 0.00 \\
\hline $\mathrm{N}$ & $\mathrm{Nsp}^{2}$ & 11.700 & 31.000 & 0.00 \\
\hline $\mathrm{N}$ & Nsp & 15.500 & 12.500 & 0.00 \\
\hline $\mathrm{N}$ & $\mathrm{Nsp}^{3}-\mathrm{S} 4$ & 12.792 & 5.295 & 0.00 \\
\hline $\mathrm{N}$ & $\mathrm{N}^{+} \mathrm{sp}^{3}$ & 15.722 & 14.277 & -0.40 \\
\hline $\mathrm{N}$ & $\mathrm{N}^{+} \mathrm{sp}^{3}-\mathrm{P} 5$ or $\mathrm{S} 6$ & 14.615 & 2.975 & -0.40 \\
\hline $\mathrm{N}$ & $\mathrm{N}^{+} \mathrm{O}_{2}^{-}$ & 7.967 & 15.621 & 0.00 \\
\hline$S$ & Sar & 9.340 & 12.157 & 0.00 \\
\hline S & $\mathrm{Ssp}^{3}$ & 10.435 & 5.126 & 0.00 \\
\hline$S$ & S6 & 4.861 & 2.920 & 0.00 \\
\hline$S$ & $\mathrm{Ssp}^{2}$ & 12.892 & 18.852 & 0.00 \\
\hline$S$ & S4 & 8.599 & 5.952 & 0.00 \\
\hline S & $\mathrm{S}^{-}$ & 3.329 & 8.156 & 1.60 \\
\hline $\mathrm{P}$ & $\mathrm{Psp}^{3}$ & 11.133 & 17.700 & 0.00 \\
\hline $\mathrm{P}$ & P5 & 4.664 & 2.951 & 0.00 \\
\hline $\mathrm{P}$ & $\mathrm{P5}^{-}$ & 2.972 & 6.209 & 1.40 \\
\hline $\mathrm{Si}$ & $\mathrm{Si}$ & 4.402 & 7.703 & 0.00 \\
\hline $\mathrm{Cl}$ & $\mathrm{Cl}$ & 11.861 & 13.647 & 0.00 \\
\hline $\mathrm{Br}$ & $\mathrm{Br}$ & 11.649 & 13.388 & 0.00 \\
\hline I & I & 11.375 & 17.898 & 0.00 \\
\hline
\end{tabular}

${ }^{a} a_{i}$ and $\boldsymbol{b}_{i}$ are the m-PEOE coefficients. $Q_{i}^{\langle 0\rangle}$ is the initial atomic partial charge.

introduced instead of the internal coordinate set, which has been widely used, as indicated in Figure 2a, for describing the angle
Table 3. Effective Atomic Polarization Parameter Set According to Atom Type Used in Eq $8^{47, a}$

\begin{tabular}{|c|c|c|c|}
\hline atom & atom type & $\alpha_{i, 0}^{*}$ & $a_{i}$ \\
\hline $\mathrm{C}$ & $\mathrm{Csp}^{2}$ (ethylene) & 1.5160 & 0.5680 \\
\hline $\mathrm{C}$ & $\mathrm{Csp}^{2}$ (aromatic) & 1.4500 & 0.7630 \\
\hline $\mathrm{C}$ & $\mathrm{Csp}^{2}$ (carbonyl) & 1.2530 & 0.8620 \\
\hline $\mathrm{C}$ & $\mathrm{Csp}^{3}$ & 1.0310 & 0.5900 \\
\hline $\mathrm{C}$ & Csp & 1.4900 & 1.1000 \\
\hline $\mathrm{H}$ & $\mathrm{Hsp}^{3}$ & 0.3960 & 0.2190 \\
\hline $\mathrm{H}$ & $\mathrm{Hsp}^{2}$ (aromatic) & 0.2980 & 0.4040 \\
\hline $\mathrm{O}$ & $\mathrm{Osp}^{2}$ & 0.7200 & 0.3470 \\
\hline $\mathrm{O}$ & $\mathrm{Osp}^{3}$ & 0.6230 & 0.2810 \\
\hline $\mathrm{N}$ & $\mathrm{Nsp}^{2}$ (aromatic, pyrrole) & 0.8710 & 0.4240 \\
\hline $\mathrm{N}$ & $\mathrm{Nsp}^{2}$ (aromatic, pyridine) & 0.6560 & 0.4360 \\
\hline $\mathrm{N}$ & $\mathrm{Nsp}^{2}$ (amide) & 0.8210 & 0.4220 \\
\hline $\mathrm{N}$ & $\mathrm{Nsp}^{3}$ & 0.9660 & 0.4370 \\
\hline $\mathrm{N}$ & Nsp & 0.9800 & 0.3100 \\
\hline $\mathrm{N}$ & $-\mathrm{N}=\mathrm{N}-$ & 0.8210 & 0.4220 \\
\hline$S$ & $\operatorname{Ssp}^{3}(-S-)$ & 2.6880 & 1.3190 \\
\hline$S$ & So & 4.3200 & 1.9954 \\
\hline$S$ & S6 & 5.1520 & -1.7304 \\
\hline $\mathrm{P}$ & P5 & 11.1010 & -7.0057 \\
\hline $\mathrm{F}$ & $\mathrm{F}$ & 0.2260 & 0.1440 \\
\hline $\mathrm{Cl}$ & $\mathrm{Cl}$ & 2.1800 & 1.0890 \\
\hline $\mathrm{Br}$ & $\mathrm{Br}$ & 3.1140 & 1.4020 \\
\hline I & I & 5.1660 & 2.5730 \\
\hline
\end{tabular}

${ }^{a} \alpha_{i, 0}^{*}$ is the atomic polarizability at zero formal-charged atom $i . a_{i}$ is the ratio by atomic partial charge.

Table 4. Classification of Lennard-Jones Potential Parameter Set According to Atom Type Used in Eq $9 \mathrm{a}^{48, a}$

\begin{tabular}{clcl} 
atom type & \multicolumn{1}{c}{ description } & $\varepsilon_{i i}(\mathrm{kcal} / \mathrm{mol})$ & $\sigma_{i i}(\AA)$ \\
H1 & aliphatic hydrogen & 0.031 & 2.628 \\
H2 & H bonded to amide & 0.094 & 2.076 \\
H3 & H bonded to aromatic system & 0.011 & 2.815 \\
H4 & hydroxyl hydrogen & 0.031 & 2.628 \\
C1 & aliphatic carbon & 0.042 & 3.697 \\
C2 & aromatic carbon & 0.096 & 3.555 \\
C3 & carbon in carboxylic group & 0.139 & 3.074 \\
C4 & carbon in amide & 0.157 & 3.011 \\
C5 & carbon in carboxylate ion & 0.088 & 2.931 \\
N1 & aromatic nitrogen with 3 bonds & 0.235 & 2.833 \\
N2 & aromatic nitrogen with 2 bonds & 0.105 & 3.118 \\
N3 & nitrogen in amide or amine & 0.157 & 3.011 \\
N4 & nitrogen in ammonium ion & 0.388 & 2.682 \\
O1 & oxygen in carboxylic or amide group & 0.226 & 2.717 \\
O2 & sp 3 oxygen & 0.200 & 2.655 \\
O3 & oxygen in carboxylate ion & 0.181 & 2.922 \\
S1 & sulfur & 0.480 & 3.554 \\
P1 & phosphorus & 0.220 & 3.800 \\
F1 & fluorine & 0.069 & 3.458 \\
C11 & chlorine & 0.069 & 3.970 \\
Br1 & bromine & 0.100 & 4.260
\end{tabular}

${ }^{a} \boldsymbol{\varepsilon}_{\mathrm{ii}}$ is the depth of the potential well. $\sigma_{\mathrm{ii}}$ is the finite distance at which the interparticle potential is zero.

dependency of a hydrogen bond. The hydrogen bond potential function of the PMFF is approximated using the 1-6-12 type function as follows: 

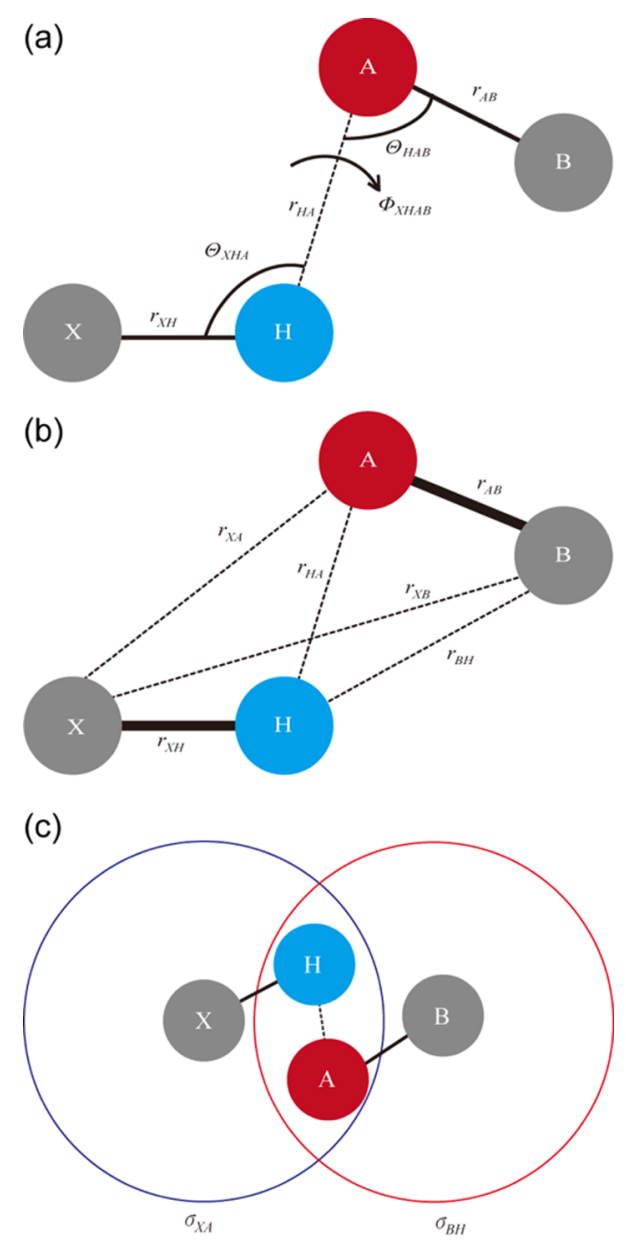

Figure 2. (a) Hydrogen bond coordinate system, $r_{\mathrm{HA}}, \theta_{\mathrm{XHA}}, \theta_{\mathrm{HAB}}$, and $\phi_{\mathrm{XHAB}}$, which is usually used to describe the hydrogen bond system. (b) Coordinate system, $r_{\mathrm{HA}}, r_{\mathrm{XA}}, r_{\mathrm{BH}}$, and $r_{\mathrm{XB}}$, which is introduced in our model for describing the hydrogen bond. (c) Repulsive cores, $\sigma_{\mathrm{XA}}$ and $\sigma_{\mathrm{BH}}$ of the $1-3$ atomic pairs for the $\mathrm{X}-\mathrm{H} \cdots \mathrm{A}=\mathrm{B}$ hydrogen bond system.

$$
V_{\mathrm{H}-\text { Bond }}=V_{\mathrm{el}}^{\mathrm{HB}}+V_{6-12}^{\mathrm{HB}}=\sum_{i>j} \frac{q_{i} q_{j}}{r_{i j}}+\sum_{k} V_{6-12}^{\mathrm{HB}}\left(r_{k}\right)
$$

where $V_{\mathrm{H}-\text { Bond }} V_{\mathrm{el}}^{\mathrm{HB}}$, and $V_{6-12}^{\mathrm{HB}}$ are the total hydrogen bond potential energy, and the electrostatic and $\mathrm{vdW}$ potential energies in the hydrogen bond, respectively, and $r_{k}$ describes the distance between atom pairs, namely, $r_{\mathrm{HA}}, r_{\mathrm{XA}}, r_{\mathrm{BH}}$, and $r_{\mathrm{XB}}$. A $\mathrm{vdW}$ potential function in a hydrogen bond potential function is the same as in a previous vdW potential function.

$$
V_{6-12}^{H B}\left(r_{k}\right)=-\frac{B_{k}}{r_{k}{ }^{6}}+\frac{D_{k}}{r_{k}^{12}}=4 \pi \varepsilon_{k}\left[-\left(\frac{\sigma_{k}}{r_{k}}\right)^{6}+\left(\frac{\sigma_{k}}{r_{k}}\right)^{12}\right]
$$

where $B_{k}, D_{k}, \varepsilon_{k}$, and $\sigma_{k}$ are Lennard-Jones parameters in one of the atomic pairs participating in the hydrogen bond. To represent the unique property of a hydrogen bond interaction, a repulsive core is applied, which was represented by a 6-12-type function. The radius of the repulsive cores (Figure 2c) is defined based on the distance of a 1-3 interaction when the hydrogen bond interaction is the most stable. If the distance in a $1-3$ interaction is shorter than the repulsive core radius defined, the hydrogen bond becomes unstable, and the energy is increased.
Table 5. Classification of Hydrogen Bond Parameter Set

\begin{tabular}{|c|c|c|c|}
\hline \multicolumn{4}{|c|}{ hydrogen bond atom type } \\
\hline atom type & \multicolumn{3}{|c|}{ description } \\
\hline $\mathrm{H} 1$ & \multicolumn{3}{|l|}{ amide hydrogen } \\
\hline $\mathrm{H} 2$ & \multicolumn{3}{|c|}{ hydrogen in $\mathrm{CO}_{2} \mathrm{H}$} \\
\hline $\mathrm{H} 3$ & \multicolumn{3}{|l|}{ bonded to $\mathrm{N}^{+}$} \\
\hline $\mathrm{C} 1$ & \multicolumn{3}{|c|}{ carbonyl carbon in carboxylic group } \\
\hline $\mathrm{C} 2$ & \multicolumn{3}{|c|}{ carbonyl carbon in amide } \\
\hline $\mathrm{C} 3$ & \multicolumn{3}{|c|}{ carbonyl carbon in carboxylate ion } \\
\hline N1 & \multicolumn{3}{|l|}{ nitrogen in amide } \\
\hline $\mathrm{N} 2$ & \multicolumn{3}{|c|}{ nitrogen in ammonium ion } \\
\hline $\mathrm{O} 1$ & \multicolumn{3}{|c|}{ carbonyl oxygen in carboxylic group } \\
\hline $\mathrm{O} 2$ & \multicolumn{3}{|c|}{ carbonyl oxygen in amide } \\
\hline $\mathrm{O} 3$ & \multicolumn{3}{|c|}{$\mathrm{sp}^{3}$ oxygen in $\mathrm{CO}_{2} \mathrm{H}$} \\
\hline $\mathrm{O} 4$ & \multicolumn{3}{|c|}{ carbonyl oxygen in carboxylate ion } \\
\hline \multicolumn{4}{|c|}{ hydrogen bond parameters } \\
\hline conformations & $\begin{array}{l}\text { interaction } \\
\text { atomic pairs }\end{array}$ & $\varepsilon(\mathrm{kcal} / \mathrm{mol})$ & $\sigma(\AA)$ \\
\hline \multirow[t]{3}{*}{ amide-amide } & $\mathrm{H} 1 \cdots \mathrm{O} 2$ & 2.325 & 1.604 \\
\hline & $\mathrm{N} 1 \cdots \mathrm{O} 2$ & 0.043 & 3.651 \\
\hline & $\mathrm{H} 1 \cdots \mathrm{C} 2$ & 0.013 & 3.609 \\
\hline \multirow{3}{*}{$\begin{array}{l}\text { carboxyl acid-carboxyl acid } \\
\text { (open-chain) }\end{array}$} & $\mathrm{H} 2 \cdots \mathrm{O} 1$ & 2.764 & 1.722 \\
\hline & $\mathrm{O} 3 \cdots \mathrm{O} 1$ & 0.052 & 3.399 \\
\hline & $\mathrm{H} 2 \cdots \mathrm{C} 1$ & 0.014 & 3.570 \\
\hline \multirow{3}{*}{$\begin{array}{l}\text { carboxyl acid-carboxyl acid } \\
\text { (cyclic) }\end{array}$} & $\mathrm{H} 2 \cdots \mathrm{O} 1$ & 4.186 & 1.515 \\
\hline & $\mathrm{O} 3 \cdots \mathrm{O} 1$ & 0.141 & 2.878 \\
\hline & $\mathrm{H} 2 \cdots \mathrm{C} 1$ & 0.017 & 3.483 \\
\hline \multirow[t]{3}{*}{ amide-carboxyl acid dimer 1} & $\mathrm{H} 2 \cdots \mathrm{O} 2$ & 3.519 & 1.732 \\
\hline & $\mathrm{O} 3 \cdots \mathrm{O} 2$ & 0.061 & 3.309 \\
\hline & $\mathrm{H} 2 \cdots \mathrm{C} 2$ & 0.015 & 3.558 \\
\hline \multirow[t]{3}{*}{ amide-carboxyl acid dimer 2} & $\mathrm{H} 1 \cdots \mathrm{O} 1$ & 2.790 & 1.437 \\
\hline & $\mathrm{N} 1 \cdots \mathrm{O} 1$ & 0.032 & 3.843 \\
\hline & $\mathrm{H} 1 \cdots \mathrm{C} 1$ & 0.015 & 3.545 \\
\hline \multirow[t]{3}{*}{ ammonuim ion-carboxylate ion } & $\mathrm{H} 3 \cdots \mathrm{O} 5$ & 4.211 & 1.648 \\
\hline & $\mathrm{N} 2 \cdots \mathrm{O} 5$ & 0.072 & 3.476 \\
\hline & $\mathrm{H} 3 \cdots \mathrm{C} 3$ & 0.029 & 2.987 \\
\hline
\end{tabular}
According to the Atom Type Used in Eq $12^{49}$

The atom types and parameters are described in Table 5. In this study, the parameters for alcohol in carboxylic acid and the nitrogen and hydrogen in amide were used to calculate the normal alcohol and amine type owing to the high structural similarity between them.

2.3. Solvation-Free Energy Calculation Model and Generalized Solvation Free Energy Density (GSFED) Model. The PMFF has a solvation-free energy model, namely, GSFED, ${ }^{50,51}$ which is well balanced with other potential energy functions. Solvation-free energy, $\Delta G_{\text {solv }}$, in the GSFED model is described using five experimental values as follows:

$$
\begin{aligned}
\Delta G_{\text {solv }}= & \sum_{k=1}^{S}\left[C_{1}\left|\sum_{i=1}^{N_{\mathrm{A}}} \frac{q_{i}}{r_{i k}{ }^{2}}\right|+C_{2} \sum_{i=1}^{N_{\mathrm{A}}} \frac{q_{i}}{r_{i k}^{3}}+C_{3} \sum_{i=1}^{N_{\mathrm{A}}} \frac{\alpha_{i}}{r_{i k}{ }^{3}}\right. \\
& +C_{4} \sum_{i=1}^{N_{\mathrm{A}}} \frac{\alpha_{i}}{r_{i k}{ }^{6}}+C_{5} B^{m} \sum_{i=1}^{N_{\mathrm{A}}} \alpha_{i}^{*}\left(\frac{4 r_{i 0}{ }^{6}}{r_{i k}{ }^{6}}-\frac{3 r_{i 0}{ }^{8}}{r_{i k}{ }^{8}}\right) \cos ^{2} \theta \\
& / N_{i}^{0}+C_{6} A^{m} \sum_{i=1}^{N_{\mathrm{A}}} \beta_{i}^{*}\left(\frac{4 r_{i 0}{ }^{6}}{r_{i k}{ }^{6}}-\frac{3 r_{i 0}{ }^{8}}{r_{i k}{ }^{8}}\right) \cos ^{2} \theta / N_{i}^{0} \\
& \left.+\frac{C_{7} \gamma^{m} S_{\mathrm{cav}}+C_{8}}{S}\right]
\end{aligned}
$$




$$
C_{j=1 \text { or } 2}^{m}=C_{j, 0} \varepsilon^{m}+C_{j, 1} \text { and } C_{j=3 \text { or } 4}^{m}=C_{j, 0} \eta^{m}+C_{j, 1}
$$

where $S$ and $N_{\mathrm{A}}$ represent the number of surface fragments on the cavity surface and atoms of the solute, $r_{i k}$ represents the distance between the $i$ th atom and the $k$ th surface fragment, $A$ and $B$ represent the $\mathrm{HB}$ acidity and basicity of the hydrogen bonded molecules, respectively, $\theta$ is the $\mathrm{HB}$ angle described in Figure $3, r_{i 0}$ is the equilibrium distance of the particular $\mathrm{HB}$ donor or acceptor atom $i, \alpha_{i}^{*}$ and $\beta_{i}^{*}$ are the effective $\mathrm{HB}$ acidity and basicity of atom $i$, respectively, $N_{i}^{0}$ is the number of surface grid points of atom $i$ that are within the surface designed by the HB angle $\theta$, and $\varepsilon^{m}$ and $\eta^{m}$ are the dielectric constant and refractive index of the solvent, respectively. The net atomic charge, $q_{i}$, and effective atomic polarizability, $\alpha_{i}$, of the $i$ th atom of the solute is calculated using m-PEOE and CDEAP. The cavity surface is represented by the sum of the solvent-accessible surface of each atom. Each solvent-accessible surface of an atom is described using the sum of the van der Waals radius and the effective solvent shell thickness. The solvent parameters used in GSFED and GSFED-HB, $C_{j}$, are described in Table 6. The
$\mathbf{A}$

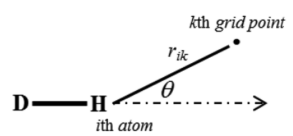

C

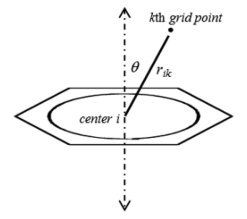

B

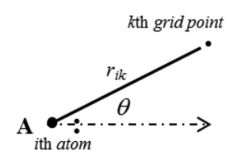

D

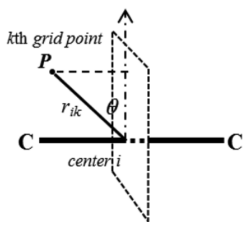

Figure 3. Description of angle $\theta$ and distance $r$ used in the GSFED-HB model: (A) hydrogen bond donor, (B) hydrogen bond acceptor, (C) aromatic groups as hydrogen bond acceptor, and (D) alkene and alkyne functional groups as hydrogen bond acceptor.

coefficients of the $\mathrm{HB}$ acidity and basicity are described in Table 7.

2.4. Software Implementation. To examine the suitability, reliability, and accuracy of the PMFF using a structural optimization and docking simulation by integrating all components of the PMFF, we developed a program using JAVA and the Chemistry Development Kit (CDK). ${ }^{55}$ The parameters used in MM3 intramolecular PEFs were taken from the internal parameter set file in Maestro. ${ }^{56}$ For the structural optimization and docking simulation, the direction of the vector searched in the geometric parameter space was calculated using the steepest descent method, ${ }^{57}$ and the size of the vector was determined using the golden section search method. ${ }^{58}$
The intermolecular potential energy is dependent on the distance and slowly converges to zero at long distances. The cutoff distance in the intermolecular PEFs was introduced into the calculation to describe these phenomena and reduce the computation time. In addition, a smooth function was introduced to maintain the continuous derivative of the PEFs, which is described as

$$
f(d)=\frac{d_{\max }-d}{d_{\max }-d_{\min }}
$$

where $d_{\min }$ and $d_{\max }$ are the minimum and maximum cutoff distances and $d$ is the distance between two atoms. When the value of $d$ is between the minimum and maximum cutoff distance, the potential energy is calculated based on the product of the smooth function and intermolecular PEF. In this validation, $d_{\min }$ was determined based on $6 \AA$ in an electrostatic PEF and $4 \AA$ in a hydrogen bond and nonbonding PEF, and $d_{\max }$ was determined based on $12 \AA$ in an electrostatic PEF and $6 \AA$ in a hydrogen bond and nonbonding PEF.

2.5. Calculation of Conformer Energy Difference for Small Molecules. MM3 force fields were developed for the accurate conformational analysis of small organic molecules. Since the MM3 was introduced to calculate the intrapotential energy portion of the PMFF, it is necessary to ensure that the PMFF maintains the accuracy in conformational analysis of organic molecules at the similar accuracy level of the MM3 even though intramolecular electrostatic and vdW PEF were incorporated in intramolecular PEF set of MM3.

To confirm this hypothesis, structures of 17 molecules were collected from Pubchem ${ }^{59}$ and are listed in Table 8. The $\Delta E_{\text {conf }}^{\exp }$ of the 17 molecules was determined by a gas-phase determination of activation enthalpy or potential energy difference $^{60}$ or solution measurements of free energy of activation. ${ }^{60}$ Since the $\Delta E_{\text {conf }}^{\exp }$ values of the 17 molecules are not enough to check whether both MM3 and PMFF gave similar levels of accuracy in conformational analysis, 133 organic ligands from the X-ray crystal structures of ligand-protein complexes were further selected from the Protein Data Bank (PDB) ${ }^{61}$ (Table S1), and then their $\Delta E_{\text {conf }}^{\mathrm{MO}}$ were calculated with an ab initio molecular orbital (MO) calculation method. The 133 compounds have molecular weights of less than 400 and the number of rotatable bonds is one or two to avoid too much conformers. Also, 133 compounds were selected in order to have maximum structural variance in the principle component space that was constructed with molecular geometrical descriptors. The counter conformers of the 133 ligands were generated by considering axial and equatorial or by considering a torsional energy barrier. The minimum energy structures, which should correspond to a local minimum, of the 300 conformers, 34 from the gas-phase experiments and 266 from ligand-protein complexes, were obtained using ab initio MO calculation with

Table 6. Generalized Solvation Free Energy Density Model Parameter Used in Eq 13

$\begin{array}{ccccc}\text { parameter } & \text { GSFED } & \text { GSFED-HB } & \text { parameter } & \text { GSFED } \\ C_{1,0} & -1.76 \times 10^{-03} & -4.41 \times 10^{-04} & C_{4,0} & 6.72 \\ C_{1,1} & -1.37 \times 10^{-01} & -3.43 \times 10^{-02} & C_{4,1} & -8.99 \\ C_{2,0} & -2.89 \times 10^{-03} & -7.23 \times 10^{-04} & C_{5} & -2.25 \\ C_{2,1} & -1.84 \times 10^{-01} & -4.59 \times 10^{-02} & C_{6} & -7.53 \\ C_{3,0} & -2.16 \times 10^{-01} & -5.40 \times 10^{-02} & C_{7} & -4.35 \\ C_{3,1} & 2.64 \times 10^{-01} & 6.61 \times 10^{-02} & C_{8} & -4.35 \\ \end{array}$

${ }^{a_{T}}$ The parameters have units that enable the product of the basis function and the coefficient to be expressed in $\mathrm{kcal} / \mathrm{mol}$. 
Table 7. Classification of Hydrogen Bond Potential Energy Function Parameter Set Used in Eq 13a ${ }^{51, a}$

\begin{tabular}{|c|c|c|c|c|c|c|c|c|c|}
\hline \multicolumn{10}{|c|}{ parameters for hydrogen bond acidity } \\
\hline type & $\alpha^{*}$ & $r_{0}(\AA)$ & $\theta<$ & $N^{0}$ & type & $\alpha^{*}$ & $r_{0}(\AA)$ & $\theta<$ & $N^{0}$ \\
\hline $\mathrm{C}_{\mathrm{sp}}-\mathrm{H}$ & 0.354 & 2.100 & 60 & 338 & $\mathrm{H}_{2} \mathrm{~N}-\mathrm{H}$ & 0.369 & 1.950 & 90 & 491 \\
\hline $\mathrm{RO}-\mathrm{H}$ & 2.434 & 1.804 & 90 & 457 & $\mathrm{C}_{\mathrm{ar}}-\mathrm{N}-\mathrm{H}$ & 0.481 & 2.100 & 90 & 377 \\
\hline $\mathrm{c}-\mathrm{O}-\mathrm{H}$ & 1.491 & 1.804 & 90 & 339 & $\mathrm{RCONH}-\mathrm{H}$ & 1.350 & 2.016 & 90 & 451 \\
\hline $\mathrm{HO}-\mathrm{H}$ & 3.039 & 1.880 & 90 & 577 & $\mathrm{RCONR}-\mathrm{H}$ & 1.006 & 1.988 & 90 & 317 \\
\hline $\mathrm{C}_{\mathrm{ar}} \mathrm{O}-\mathrm{H}$ & 3.893 & 1.724 & 90 & 390 & $\mathrm{HCONH}-\mathrm{H}$ & 1.454 & 2.016 & 90 & 470 \\
\hline $\mathrm{RCOO}-\mathrm{H}$ & 6.595 & 1.629 & 90 & 438 & HCONR-H & 1.614 & 1.988 & 90 & 417 \\
\hline $\mathrm{HCOO}-\mathrm{H}$ & 8.129 & 1.629 & 90 & 439 & $\mathrm{~N}_{\mathrm{ar}}-\mathrm{H}$ & 1.356 & 1.988 & 30 & 88 \\
\hline $\mathrm{RHN}-\mathrm{H}$ & 0.309 & 2.120 & 90 & 419 & $\mathrm{SO}_{2} \mathrm{NH}-\mathrm{H}$ & 2.606 & 1.710 & 90 & 380 \\
\hline $\mathrm{R}_{2} \mathrm{~N}-\mathrm{H}$ & 0.284 & 2.140 & 90 & 359 & $\mathrm{SO}_{2} \mathrm{NR}-\mathrm{H}$ & 1.013 & 1.710 & 90 & 306 \\
\hline $\mathrm{CONR}-\mathrm{H}$ & 0.543 & 1.988 & 30 & 88 & & & & & \\
\hline \multicolumn{10}{|c|}{ parameters for hydrogen bond basicity } \\
\hline type & $\beta^{*}$ & $r_{0}(\AA)$ & $\theta<$ & $N^{0}$ & type & $\beta^{*}$ & $r_{0}(\AA)$ & $\theta<$ & $N^{0}$ \\
\hline$-\mathrm{C}_{\mathrm{sp}}{ }^{2}$ & 0.066 & 3.570 & 30 & 1039 & $-\mathrm{NH}_{2}$ & 1.397 & 2.840 & 60 & 404 \\
\hline $\mathrm{c}-\mathrm{C}_{\mathrm{sp}}{ }^{2}$ & 0.085 & 3.570 & 30 & 657 & $-\mathrm{NRH}$ & 1.283 & 2.890 & 60 & 318 \\
\hline$-\mathrm{C}_{\mathrm{ar}}$ & 0.076 & 3.400 & & & $\mathrm{NR}_{3}$ & 1.260 & 2.900 & 60 & 233 \\
\hline $\mathrm{C}_{\mathrm{sp}}{ }^{3}-\mathrm{C}_{\mathrm{ar}}$ & 0.306 & 3.400 & & & $\mathrm{NH}_{3}$ & 1.215 & 2.840 & 60 & 484 \\
\hline$-\mathrm{C}_{\mathrm{sp}}$ & 0.080 & 3.350 & 30 & 1102 & $\mathrm{~N} / \mathrm{O}-\mathrm{C}_{\mathrm{ar}}$ & 0.793 & 3.400 & & \\
\hline $\mathrm{C}_{\mathrm{sp}}{ }^{3}-\mathrm{F}$ & 0.006 & 3.070 & 90 & 844 & $\mathrm{RCO}-\mathrm{NH}_{2}$ & 0.874 & 2.840 & 90 & 856 \\
\hline $\mathrm{C}_{\mathrm{sp}}{ }^{3}-\mathrm{Cl}$ & 0.070 & 3.196 & 90 & 971 & $\mathrm{RCO}-\mathrm{NHR}$ & 1.378 & 2.840 & 90 & 745 \\
\hline $\mathrm{C}_{\mathrm{sp}}{ }^{3}-\mathrm{Br}$ & 0.283 & 3.470 & 90 & 1081 & $\mathrm{RCO}-\mathrm{NR}_{2}$ & 1.674 & 2.840 & 90 & 741 \\
\hline $\mathrm{C}_{\mathrm{sp}}{ }^{3}-\mathrm{I}$ & 0.640 & 3.610 & 90 & 1081 & $\mathrm{HCO}-\mathrm{NH}_{2}$ & 1.108 & 2.840 & 90 & 869 \\
\hline $\mathrm{RC}(=\mathrm{O})-\mathrm{OH}$ & 0.143 & 2.940 & 60 & 779 & $\mathrm{HCO}-\mathrm{NHR}$ & 0.891 & 2.840 & 90 & 766 \\
\hline $\mathrm{RC}(=\mathrm{O})-\mathrm{OR}$ & 0.257 & 2.940 & 60 & 523 & $\mathrm{HCO}-\mathrm{NR}_{2}$ & 1.454 & 2.840 & 90 & 766 \\
\hline $\mathrm{C}_{\mathrm{ar}}-\mathrm{F}$ & 0.080 & 3.070 & 90 & 915 & $\mathrm{RC} \equiv \mathrm{N}$ & 1.391 & 2.940 & 60 & 1272 \\
\hline $\mathrm{C}_{\mathrm{ar}}-\mathrm{Cl}$ & 0.028 & 3.196 & 90 & 1021 & $\mathrm{C}_{\mathrm{sp}}{ }^{3}-\mathrm{NO}-\mathrm{O}$ & 0.342 & 3.040 & 90 & 843 \\
\hline $\mathrm{C}_{\mathrm{ar}}-\mathrm{Br}$ & 0.032 & 3.470 & 90 & 1100 & $\mathrm{C}_{\mathrm{ar}}-\mathrm{NO}-\mathrm{O}$ & 0.205 & 3.040 & 90 & 767 \\
\hline $\mathrm{C}_{\mathrm{ar}}-\mathrm{I}$ & 0.020 & 3.610 & 90 & 1086 & $\mathrm{~N}_{\mathrm{ar}}$ & 0.337 & 2.950 & 30 & 130 \\
\hline $\mathrm{R}-\mathrm{OH}$ & 0.931 & 2.931 & 60 & 751 & $\mathrm{~N}_{\mathrm{ar}}-\mathrm{H} / \mathrm{R}$ & 0.577 & 2.905 & 40 & - \\
\hline $\mathrm{c}-\mathrm{OH}$ & 0.100 & 2.831 & 60 & 624 & $-\mathrm{SH}$ & 0.482 & 3.310 & 60 & 1162 \\
\hline $\mathrm{H}_{2} \mathrm{O}$ & 0.605 & 2.852 & 60 & 852 & $\mathrm{R}_{2} \mathrm{~S}$ & 0.514 & 3.530 & 60 & 1130 \\
\hline $\mathrm{C}_{\mathrm{ar}}-\mathrm{OH}$ & 0.163 & 2.890 & 60 & 688 & RSSR & 0.252 & 3.530 & 60 & 984 \\
\hline $\mathrm{R}_{2} \mathrm{O}$ & 0.760 & 2.910 & 60 & 618 & $\mathrm{RSO}_{2}-\mathrm{NHR}$ & 1.547 & 2.854 & 90 & 872 \\
\hline $\mathrm{R}_{2} \mathrm{C}=\mathrm{O}$ & 1.184 & 2.840 & 90 & 833 & $\mathrm{RSO}_{2}-\mathrm{NHR}$ & 0.250 & 2.840 & 60 & 355 \\
\hline $\mathrm{RCHO}$ & 0.846 & 2.840 & 90 & 854 & $\mathrm{RSO}_{2}-\mathrm{NR}_{2}$ & 0.205 & 2.854 & 90 & 745 \\
\hline $\mathrm{c}-\mathrm{C}=\mathrm{O}$ & 1.072 & 2.840 & 90 & 845 & $\mathrm{RSO}_{2}-\mathrm{NR}_{2}$ & 1.886 & 2.890 & 60 & 224 \\
\hline $\mathrm{HC}(\mathrm{OR})=\mathrm{O}$ & 0.462 & 2.840 & 90 & 741 & $c-\mathrm{R}_{2} \mathrm{O}$ & 0.319 & 2.910 & 60 & 155 \\
\hline $\mathrm{RC}(\mathrm{OR})=\mathrm{O}$ & 0.842 & 2.840 & 90 & 733 & aromatic ring & & 3.400 & 40 & 667 \\
\hline $\mathrm{RC}(=\mathrm{O})-\mathrm{OH}$ & 0.792 & 2.840 & 90 & 866 & $\mathrm{O}_{\mathrm{ar}}$ & 0.059 & 2.910 & 30 & 117 \\
\hline $\mathrm{HC}(=\mathrm{O})-\mathrm{OH}$ & 0.070 & 2.840 & 90 & 876 & $\mathrm{~S}_{\mathrm{ar}}$ & 0.041 & 3.530 & 30 & 118 \\
\hline $\mathrm{CONR}_{2}$ & 0.007 & 2.840 & 90 & 849 & & & & & \\
\hline
\end{tabular}

${ }^{a} r_{0}$ is the equilibrium distance of the particular HB donor or acceptor atom i. $\theta$ is the angle described by Figure 3. If $\theta$ is bigger than the parameter, $\mathrm{HB}$ acidity or basicity is zero. $N^{0}$ is the maximum number of surface grid points of the atom that are within the range of the HB angle $\theta$ used in eq $13 \mathrm{a}$.

a $\mathrm{HF} / 6-31 \mathrm{G}^{* *}$ basis set. Since the number of experimentally obtained energy differences between the conformers of the molecules that are the analogues of proteins is limited, the authors could have collected only gas-phase experimental data of 17 molecules. The $\Delta E_{\text {conf }}^{\mathrm{MO}}$ values of the 133 organic compounds were calculated using the conformer energy difference of the pair conformers using density functional theory (DFT) with B3LYP/6-31G** in Gaussian09. The 266 minimum energy conformer structures were used as the initial structure for the geometry optimization with MM3 and PMFF. Since the steepest descent algorithm keeps the local minimum, the structural change is not great. When the root-mean-square distance (RMSD) is smaller than $10^{-4} \AA$ /atom, then the geometry optimization stops. Since both $\Delta E_{\text {conf }}^{\exp }$ and $\Delta E_{\text {conf }}^{\mathrm{MO}}$ were obtained at the gas phase, the dielectric constant was set to 1 for the MM3 and PMFF calculations. The MM3 conformer energy difference, $\Delta E_{\mathrm{conf}}^{\mathrm{MM}}$, corresponds to the energy difference between the minimum energy conformers calculated with MM3. The $\Delta E_{\text {conf }}^{\mathrm{PMFF}}$, the conformational energy difference calculated with PMFF, was calculated in the same way as the $\Delta E_{\text {conf }}^{\mathrm{MM} 3}$. The $\Delta E_{\text {conf }}$ values obtained with experiments, MM3, and PMFF are summarized in Table 8 . The $\Delta E_{\text {conf }}^{\mathrm{MO}}$ values of the 133 compounds are summarized in Table 22 together with $\Delta E_{\text {conf }}^{\mathrm{MM} 3}$ and $\Delta E_{\text {conf }}^{\mathrm{PMFF}}$.

2.6. Molecular Docking Simulation. In docking simulation, even if the target protein is assumed rigid and the energy minimum structure is obtained with the ligand's translational and rotational motion and its internal degrees of freedom, it is very difficult to find the global minimum of the PES of the complex structure due to the multiple minima problem. Thus, in this docking simulation, it is assumed that the structure of the 
Table 8. Conformer Energy Difference (kcal/mol) Compared between MM3 and PMFF

\begin{tabular}{|c|c|c|c|c|c|}
\hline \multirow[b]{2}{*}{ molecule $^{a}$} & \multirow[b]{2}{*}{$\Delta G_{\text {confer }}^{\exp } b$} & \multicolumn{2}{|c|}{$\mathrm{MM}^{\mathrm{c}}$} & \multicolumn{2}{|c|}{ PMFF } \\
\hline & & $\Delta G_{\text {confer }}^{\mathrm{MM} 3}$ & $\left|\begin{array}{l}\Delta G_{\text {confer }}^{\exp } \\
-\Delta G_{\text {confer }}^{\mathrm{MM} 3}\end{array}\right|$ & $\Delta G_{\text {confer }}^{\mathrm{PMFF}}$ & $\mid \begin{array}{l}\Delta G_{\text {confer }}^{\exp } \\
-\Delta G_{\text {confer }}^{\text {PMFF }}\end{array}$ \\
\hline 2,3-dimethylbutane (a-g) & -0.05 & -0.03 & 0.02 & 1.47 & 1.52 \\
\hline butane (a-g) & -0.97 & -0.55 & 0.42 & -0.84 & 0.13 \\
\hline cyclohexanamine (ax-eq) & 1.49 & 2.63 & 1.14 & 2.31 & 0.82 \\
\hline methoxyethane (a-g) & -1.50 & -1.76 & 0.26 & -2.50 & 1.00 \\
\hline ethanol (a-g) & -0.70 & -0.72 & 0.02 & -1.01 & 0.31 \\
\hline propanol (a-g) & -0.30 & -0.62 & 0.32 & -0.04 & 0.26 \\
\hline methyl acetate (cis-trans) & -8.00 & -6.90 & 1.10 & -9.70 & 1.70 \\
\hline 1,3,5-trineopentylbenezene (allsyn-twosyn) & -1.04 & 0.36 & 1.40 & -0.01 & 1.03 \\
\hline 2-methoxyoxane (ax-eq) & -1.00 & -1.48 & 0.48 & -2.15 & 1.15 \\
\hline 2-methylpiperidine (ax-eq) & 2.50 & 2.58 & 0.08 & 2.86 & 0.36 \\
\hline 3-methylpiperidine (ax-eq) & 1.60 & 1.44 & 0.16 & 1.74 & 0.14 \\
\hline 4-methylpiperidine (ax-eq) & 1.93 & 1.66 & 0.27 & 2.03 & 0.10 \\
\hline cis-1,3-dimethylcyclohexane (ax,ax-eq,eq) & 5.50 & 5.74 & 0.24 & 5.56 & 0.06 \\
\hline methylcyclohexane (ax-eq) & 1.75 & 1.66 & 0.09 & 1.89 & 0.14 \\
\hline$N, N$-dimethylcyclohexanamine (ax-eq) & 1.31 & 0.96 & 0.35 & 0.90 & 0.41 \\
\hline$N$-methylpiperidine (ax-eq) & 3.20 & 2.63 & 0.57 & 3.26 & 0.06 \\
\hline trans-1,2-dimethylcyclohexane (ax,ax-eq,eq) & 2.58 & 2.31 & 0.27 & 2.38 & 0.20 \\
\hline average & & & 0.46 & & 0.56 \\
\hline standard deviation & & & 0.43 & & 0.54 \\
\hline
\end{tabular}

${ }^{a}$ a: anti, g: gauche, ax: axial, eq: equatorial. ${ }^{b}$ Experimental conformer energy taken from ref $60 .{ }^{c}$ Version of MM3 is made in 2006 with 1.6.

ligand in the complex will be similar to the ligand's stable conformers. The suitability of the PMFF for protein-ligand interaction studies can be determined by the agreement between the X-ray structure of the protein-ligand complex and the PMFF global minimum energy structure of the complex. However, due to the multiple minima problem, it is very difficult to obtain the global energy minimum of a proteinligand complex using any kind of computer simulation. To overcome this problem, a multistep docking algorithm, PMFFMDA (PMFF multistep docking algorithm), was devised and the minimum energy structures of the protein-ligand complex were calculated and compared with the X-ray structure of the complex. The designed algorithm can be divided into two blocks each consisting of a few steps. The algorithm is explained in Figure 4.

To determine how well the PMFF-MDA and Glide programs predict the experimentally obtained protein-ligand complex structure, 214 protein-ligand complex structures, a test set used in the development of the Glide program, were collected from PDB. Then, the missing hydrogens of the complexes were added using Maestro. ${ }^{56}$ In order to explore the high dimensional potential energy surface of protein-ligand interaction, various conformers of the ligand were used as the initial structure of the docking simulation. To generate ligand conformers, the rotatable bonds in the ligand were identified using a SMART $^{62}$ key and then rotated at an interval of $60^{\circ}$, with the number of the generated conformers denoted as $M$. When the energy of the generated conformer is greater or less than $1 \mathrm{kcal}$ compared to the energy of the ligand structure of the complex, the confirmer was removed from the ligand structure pool for the initial structures of docking simulations.

The docking procedure of the PMFF-MDA is described in Figure 5. It was assumed that the distance at which the atoms of a ligand reach maximum interaction with a protein is $2 \AA$ plus the van der Waals surface of the protein, Interaction Surface (IS). (A) Based on the assumption, IS was generated and grid points

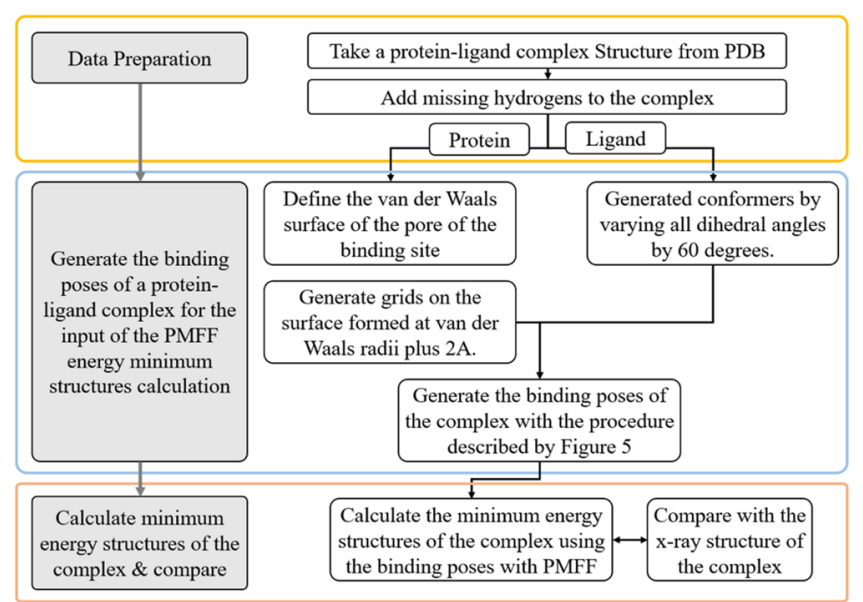

Figure 4. Flow diagram of the molecular docking simulation algorithm devised in this work. The procedure of the generation of the binding poses is described in Figure 5.

were generated on the IS with an interval $0.1 \AA$. Then, the grid points were indexed as $P_{I, J}$, which is the Jth point of the Ith amino acid in the binding pocket. (B) The atoms in the ligand are numbered $k$, and the atom type of the m-PEOE, $l$, was assigned where the $k$ th atom with the $l$ th atom type is donated as $l_{k}$, as shown in Table b- 1 . Then, the atom type, $l$, of the ligand's atoms was collected, and each atom, $k$, was assigned to one of the atom types $\left(l_{1}, l_{2}, \ldots, l_{n}\right)$ as shown in Table b-1 $[(1: 1,5),(2: 2,3,4)$, (3:6), (4:7), (5:8), (6:9)]. (C) The interaction energy at all the grid points, $P_{I, J} s$, was calculated with all kinds of atom types $\left(l_{1}\right.$, $\left.l_{2}, \ldots, l_{n}\right)\left\{E\left(P_{I, J}, l_{m}\right)\right.$, forallI\&J, $\left.m=1, n\right\}$. (D) For every atomtype $l$, the top- $N$ was selected; here, as an example where $N=3$, energetically stable grid points were selected, three from $\left\{E\left(P_{I, J}\right.\right.$, $\left.\left.l_{m}\right)\right\}$ for each $l,\left\{E\left(P_{I 1, J 1}, l_{m}\right), E\left(P_{I 2, J 2}, l_{m}\right), E\left(P_{I 3, J 3}, l_{m}\right)\right\}$, as described in Table $\mathrm{d}-1$. (E) All the energetically favorable binding modes of each conformer ( $M$ conformers) were 
(A) Grid generation

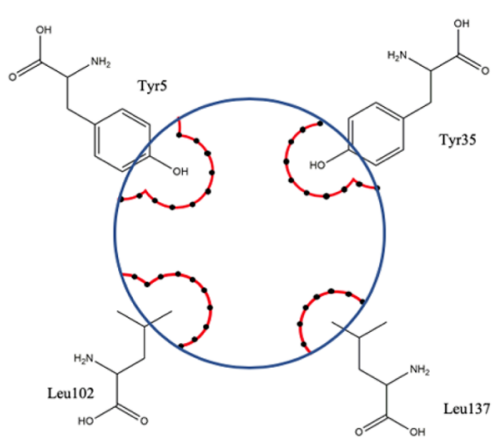

(C) Inter-atomic potential energy calculation

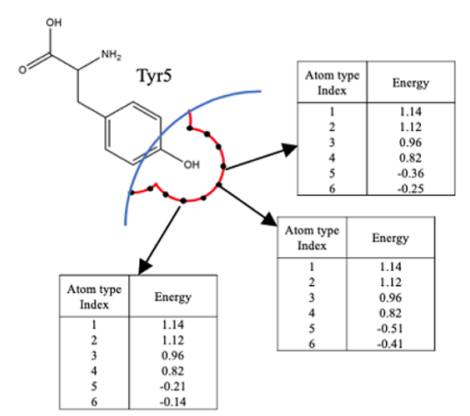

(E) Binding mode generation

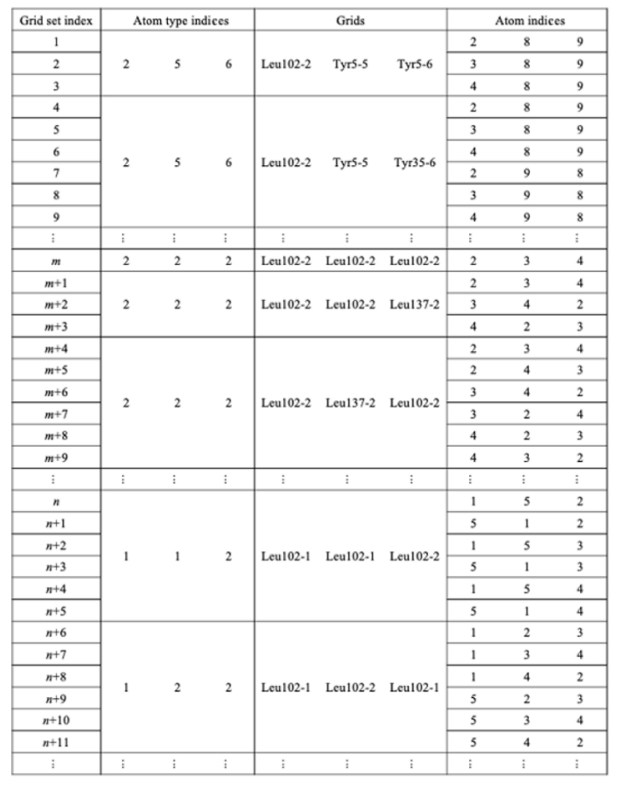

Table e-1. Binding mode
(B) Determination of atom types of ligand

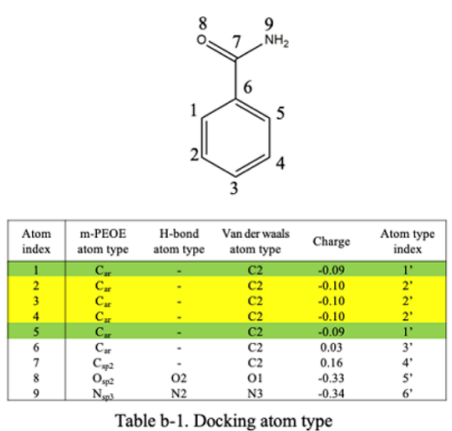

(D) Selection Top-k grids by each atom types
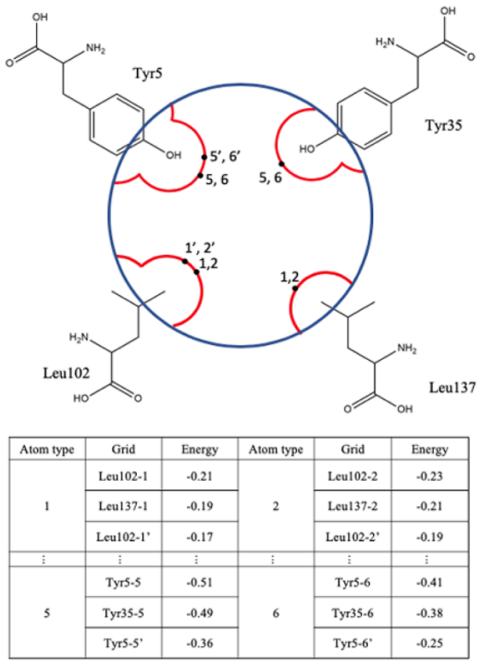

Table d-1. Selected energetically stable grid points

(F) Binding pose generation and Energy calculation by each binding pose
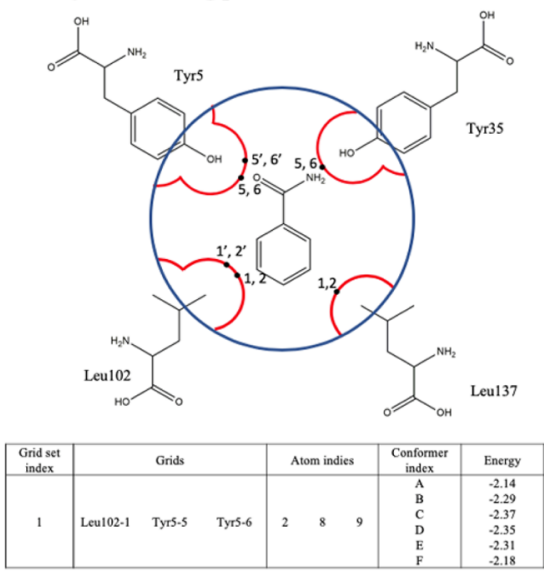

Table f-1. Total potential energy for generated binding pose using PMFF

Figure 5. Description of protocol of binding pose generation. (a) Grids are generated. Red lines describe atomic surface. Blue lines describe userselected pore of binding sites. Black circles describe grids. (b) Docking atom types for each atom of ligands are determined by atomic partial charge and atom types used in m-PEOE, HB, and vdW PEFs. (c) Interatomic potential energy is calculated when atom-defined docking atom type is located on the grid. (d) Top- $k$ grids for each docking atom type are selected in order of low interatomic potential energy. (e) Grid sets to generate binding poses using an alignment algorithm are generated by combination of the Top- $N$ grids and the docking atom types. (f) Binding pose is generated to align between grids and ligand atoms about all structures of conformers, and binding affinity about generated binding poses are calculated using PMFF.

generated through the following procedure. (i) All the possible combinations of the three atom types from the $n$ atom-types were generated, $\left(l_{m 1}, l_{m 2}, l_{m 3}\right)$, with ${ }_{n} C_{3}$ combinations. (ii) For each possible combination, $\left(l_{m 1}, l_{m 2}, l_{m 3}\right)$,three grid points were assigned in step (D), $\left\{\left(P_{I 1, J 1}, l_{m 1}\right),\left(P_{I 2, J 2}, l_{m 2}\right),\left(P_{I 3, J 3}, l_{m 3}\right)\right\}$, then all the possible grid point combinations of the of each atom-type combination became 27. For example, one of the 27 combination is $\left\{\left(l_{m 1}, l_{m 2}, l_{m 3}\right),\left(P_{I 1, J 1}, l_{m 1}\right),\left(P_{I 2, J 2}, l_{m 2}\right),\left(P_{I 3, J 3}\right.\right.$, $\left.\left.l_{m 3}\right)\right\}$, and this combination index means $P_{I 1, J 1}$ grid from atomtype $l_{m 1}, P_{I 2, J 2}$ grid from atom-type $l_{m 2}$, and $P_{I 3, J 3}$ grid from atom- 
type $l_{m 3}$. (iii) The atom-type index is replaced with the atomic index of the ligand. Since more than one atom of the ligand was assigned to one atom type, a large number of the combinations were generated as $\left\{\left(k_{l m 1}, k_{l m 2}, k_{l m 3}\right),\left(P_{I 1, J 1}, l_{m 1}\right),\left(P_{I 2, J 2}, l_{m 2}\right)\right.$, $\left.\left(P_{I 3, J 3}, l_{m 3}\right)\right\}$, which is described in the last column of Table e- 1 . (F) By minimizing the following function,

$$
\begin{aligned}
\mathrm{D} 2= & {\left[\left\{\vec{X}\left(k_{l m 1}\right)-\vec{X}\left(P_{I 1, J 1}, l_{m 1}\right)\right\}^{2}\right.} \\
& -\left\{\vec{X}\left(k_{l m 2}\right)-\vec{X}\left(P_{I 2, J 2}, l_{m 2}\right)\right\}^{2} \\
& \left.-\left\{\vec{X}\left(k_{l m 3}\right)-\vec{X}\left(P_{I 3, J 3}, l_{m 3}\right)\right\}^{2}\right]
\end{aligned}
$$

the triangles, $\left(k_{l m 1}, k_{l m 2}, k_{l m 3}\right)$ and $\left\{\left(P_{I 1, J 1}, l_{m 1}\right),\left(P_{I 2, j 2}, l_{m 2}\right)\right.$, $\left.\left(P_{I 3, J 3}, l_{m 3}\right)\right\}$ have the maximum overlap. Since the protein structure was fixed during docking simulation, only the translation and orientation of the triangle of $\left(k_{l m 1}, k_{l m 2}, k_{l m 3}\right)$ is changed during the D2 minimization. Using $\left(k_{l m 1}, k_{l m 2}, k_{l m 3}\right)$, the geometry of the ligand can be generated. The total potential energy about generated geometries of protein-ligand was calculated by PMFF and used in docking score. The performance of the docking simulation was evaluated with the RMSD between the X-ray structure and generated binding pose of the ligand. The RMSD was calculated only with heavy atomic positions. The top-ranked pose and closest pose, described in Table 10, were defined to be the binding pose having the lowest total potential energy and RMSD among generated geometries of the 4protein-ligand complex.

\section{RESULT AND DISCUSSION}

3.1. Calculation of Conformer Energy Difference for Small Molecules. To examine the suitability of the intramolecular potential energy function, the conformer energy difference was calculated using MM3 and PMFF for 17 organic compounds (Table 8) and 133 organic compounds (Table S1), and the difference in conformer energy was compared between MM3 and the PMFF. According to this measure, the m-PEOE charge model is suitable for use with the intramolecular potential energy. The average absolute error between the experiment and prediction was $0.46 \pm 0.43 \mathrm{kcal} / \mathrm{mol}$ in MM3 and $0.56 \pm 0.54$ $\mathrm{kcal} / \mathrm{mol}$ in the PMFF and that between the quantum mechanical data and prediction was $1.93 \pm 1.73 \mathrm{kcal} / \mathrm{mol}$ in MM3 and $1.70 \pm 1.36 \mathrm{kcal} / \mathrm{mol}$ in the PMFF.

The reason for the suitability and accuracy is that the m-PEOE charge model was developed to be focused on the dipole and quadrupole moment data. In general, an accurate dipole or quadrupole moment calculation depends on an accurate molecular structure and atomic partial charge. If the types of atoms or chemical bonds are the same but the surrounding atoms and chemical bonds are different, the atomic partial charge will be slightly different, which affects the charge distribution of the molecule. The m-PEOE charge model can explain the charge distribution of the molecule according to the chemical bond and atom type; therefore, it can examine not only the interactions between the two target systems using the intermolecular potential energy but also the molecular stability using the intramolecular potential energy.

3.2. Molecular Docking Simulation. If the intermolecular PEFs express the energy-stable protein-ligand complex structure well, the structure calculated using a docking simulation is the same as the experimental crystal structure, and the RMSD, which expresses the difference between two structures, is zero.
First, to evaluate the accuracy of the initial binding pose determination, the geometries of co-crystallized ligands were reproduced through a docking simulation taken from a set of 214 PDB complexes. The RMSD between the experimental crystal structure and the reproduced structure was compared between Glide and the PMFF. The scoring function in Glide, which is used to evaluate the similarity with the experimental structure, consists of a weighted potential energy function in the OPLS. In the PMFF, the scoring function was replaced with the potential energy for each complex. Table 9 describes the distribution of the rotatable bond and the number of conformers for 214 ligands. A rotatable bond for a ligand was distributed from zero to 24 . The number of conformers for a ligand was distributed from 1 to 36,982. The average RMSD for the top-ranked pose was smaller in the ligand with a greater number of rotatable bonds. Because the conformer, whose absolute potential energy difference between the generated conformer and the experimental structure is lower than $1.00 \mathrm{kcal} / \mathrm{mol}$, was removed in the PMFF, the number of conformers was not related to the number of rotatable bonds. The average RMSD for the topranked pose increases with the number of conformers. Table 10

Table 9. Distribution of Number of Rotatable Bonds and

\begin{tabular}{|c|c|c|c|}
\hline \multicolumn{4}{|c|}{ distribution of number of rotatable bonds } \\
\hline \multirow[b]{2}{*}{ no. of rotatable bonds } & \multirow[b]{2}{*}{ no. of cases } & \multicolumn{2}{|c|}{$\begin{array}{c}\text { average RMSD top-ranked } \\
\text { pose }(\AA)\end{array}$} \\
\hline & & Glide & PMFF \\
\hline $0-3$ & 73 & 1.28 & 1.90 \\
\hline $4-7$ & 70 & 1.40 & 2.11 \\
\hline 8 & 70 & 2.91 & 1.71 \\
\hline \multicolumn{4}{|c|}{ distribution of number of conformers } \\
\hline & & \multicolumn{2}{|c|}{$\begin{array}{c}\text { average RMSD top-ranked } \\
\text { pose }(\AA)\end{array}$} \\
\hline no. of conformer & no. of cases & Glide & PMFF \\
\hline 1 & 90 & 1.70 & 1.99 \\
\hline $2-50$ & 94 & 1.76 & 2.11 \\
\hline 51 & 30 & 2.67 & 2.54 \\
\hline
\end{tabular}
Conformers for Molecular Docking Simulation on 214 PDB Complexes

describes the docking simulation results for the 214 PDB complexes. The average of the RMSD for the top-ranked binding pose was $1.86 \pm 2.31 \AA$ in Glide and $2.12 \pm 0.67 \AA$ in the PMFF. The average of the RMSD for the closest binding pose for a co-crystallized ligand in each complex was $0.82 \pm 0.79 \AA$ in Glide and $1.53 \pm 0.58 \AA$ in the PMFF.

The performance of the docking simulation was described based on the performance of the scoring function and the binding pose search algorithm. The scoring function is considered more accurate because the RMSD for a top-ranked binding pose is small. In addition, the binding pose search algorithm is considered more accurate because the RMSD for the closest binding pose for an X-ray structure is also small. To evaluate the performance of a force field, not only the performance of the scoring function but also the difference in RMSD between the top-ranked and closest binding pose is important. Although the average RMSD for the top-ranked binding pose in the PMFF is bigger than that in Glide, the average difference in RMSD between the top-ranked and closest binding poses in the PMFF was smaller than that in Glide. The 
Table 10. RMSD ( $\AA$ ) for Glide and PMFF for Members of Glide Test Set ${ }^{a}$

\begin{tabular}{|c|c|c|c|c|c|c|}
\hline \multirow[b]{2}{*}{ PDB ID } & \multirow[b]{2}{*}{$\begin{array}{l}\text { ligand } \\
\text { atoms }\end{array}$} & \multirow[b]{2}{*}{$\begin{array}{l}\text { rot. } \\
\text { bonds }\end{array}$} & \multicolumn{2}{|c|}{ Glide } & \multicolumn{2}{|c|}{ PMFF } \\
\hline & & & $\begin{array}{l}\text { top- } \\
\text { ranked } \\
\text { pose }\end{array}$ & $\begin{array}{l}\text { closest } \\
\text { pose }\end{array}$ & $\begin{array}{l}\text { top- } \\
\text { ranked } \\
\text { pose }\end{array}$ & $\begin{array}{c}\text { closest } \\
\text { pose }\end{array}$ \\
\hline $121 \mathrm{P}$ & 46 & 8 & 1.57 & 0.71 & 2.94 & 2.18 \\
\hline $1 \mathrm{AAQ}$ & 91 & 21 & 1.30 & 1.23 & 1.49 & 1.20 \\
\hline $1 \mathrm{ABE}$ & 20 & 0 & 0.17 & 0.17 & 1.51 & 0.90 \\
\hline $1 \mathrm{ABF}$ & 23 & 0 & 0.20 & 0.06 & 1.62 & 1.37 \\
\hline $1 \mathrm{ACJ}$ & 29 & 0 & 0.28 & 0.14 & 2.36 & 1.78 \\
\hline $1 \mathrm{ACM}$ & 22 & 7 & 0.29 & 0.24 & 2.01 & 1.73 \\
\hline $1 \mathrm{ACP}$ & 16 & 4 & 1.02 & 0.51 & 1.89 & 1.26 \\
\hline $1 \mathrm{ADD}$ & 33 & 2 & 0.53 & 0.42 & 2.33 & 1.66 \\
\hline $1 \mathrm{ADF}$ & 68 & 11 & 11.25 & 2.29 & 3.22 & 2.15 \\
\hline 1AHA & 15 & 0 & 0.11 & 0.07 & 1.75 & 1.70 \\
\hline 1AKE & 83 & 16 & 3.35 & 2.06 & 3.84 & 3.71 \\
\hline $1 \mathrm{APB}$ & 23 & 0 & 0.18 & 0.06 & 0.82 & 0.81 \\
\hline $1 \mathrm{APT}$ & 84 & 21 & 0.58 & 0.58 & 3.17 & 2.66 \\
\hline $1 \mathrm{APU}$ & 81 & 19 & 1.18 & 0.68 & 3.00 & 1.35 \\
\hline $1 \mathrm{APV}$ & 80 & 18 & 1.47 & 1.47 & 0.60 & 0.60 \\
\hline $1 \mathrm{APW}$ & 79 & 18 & 0.42 & 0.42 & 2.80 & 2.37 \\
\hline 1ATL & 47 & 10 & 0.94 & 0.94 & 2.99 & 2.71 \\
\hline $1 \mathrm{AVD}$ & 31 & 5 & 0.52 & 0.27 & 1.48 & 0.91 \\
\hline 1B6K & 103 & 13 & 2.04 & 1.68 & 1.07 & 0.98 \\
\hline 1B6L & 82 & 8 & 1.06 & 1.06 & 2.92 & 0.92 \\
\hline $1 \mathrm{~B} 6 \mathrm{M}$ & 92 & 12 & 1.40 & 1.09 & 0.73 & 0.65 \\
\hline $1 \mathrm{BAP}$ & 20 & 0 & 0.23 & 0.19 & 1.68 & 1.12 \\
\hline $1 \mathrm{BBP}$ & 77 & 11 & 4.96 & 1.72 & 1.66 & 1.05 \\
\hline $1 \mathrm{BKM}$ & 77 & 19 & 2.24 & 1.16 & 2.83 & 2.70 \\
\hline 1BRA & 18 & 1 & 0.36 & 0.26 & 1.95 & 1.68 \\
\hline 1BYB & 87 & 10 & 10.49 & 1.66 & 0.77 & 0.77 \\
\hline $1 \mathrm{C} 3 \mathrm{I}$ & 63 & 14 & 0.69 & 0.69 & 0.73 & 0.73 \\
\hline $1 \mathrm{C} 5 \mathrm{P}$ & 18 & 1 & 0.21 & 0.15 & 1.74 & 1.51 \\
\hline $1 \mathrm{C} 83$ & 24 & 4 & 0.13 & 0.12 & 2.63 & 1.73 \\
\hline $1 \mathrm{C} 84$ & 26 & 4 & 0.24 & 0.21 & 2.32 & 1.79 \\
\hline $1 \mathrm{C} 86$ & 25 & 4 & 0.20 & 0.15 & 2.28 & 1.09 \\
\hline 1C87 & 25 & 4 & 0.24 & 0.20 & 2.35 & 0.90 \\
\hline $1 \mathrm{C} 88$ & 27 & 4 & 0.23 & 0.22 & 2.43 & 2.35 \\
\hline $1 \mathrm{C} 8 \mathrm{~K}$ & 49 & 2 & 5.42 & 0.68 & 2.66 & 1.18 \\
\hline $1 \mathrm{CBS}$ & 49 & 5 & 1.96 & 0.45 & 3.19 & 1.51 \\
\hline $1 \mathrm{CBX}$ & 25 & 5 & 0.36 & 0.32 & 2.23 & 1.56 \\
\hline $1 \mathrm{CDE}$ & 54 & 10 & 1.29 & 0.94 & 2.72 & 2.45 \\
\hline $1 \mathrm{CDG}$ & 45 & 4 & 3.98 & 3.71 & 1.98 & 1.43 \\
\hline $1 \mathrm{COM}$ & 28 & 4 & 3.64 & 2.83 & 1.99 & 1.37 \\
\hline $1 \mathrm{COY}$ & 49 & 0 & 0.28 & 0.14 & 2.34 & 1.26 \\
\hline 1CTR & 53 & 5 & 3.56 & 2.31 & 2.04 & 1.64 \\
\hline $1 \mathrm{CTT}$ & 30 & 2 & 4.93 & 1.86 & 2.05 & 1.91 \\
\hline 1D3D & 75 & 9 & 3.25 & 1.50 & 3.15 & 1.13 \\
\hline 1D3P & 78 & 11 & 2.37 & 1.15 & 3.05 & 1.29 \\
\hline 1DBB & 55 & 1 & 0.41 & 0.22 & 2.48 & 1.89 \\
\hline 1DBJ & 51 & 0 & 0.20 & 0.18 & 0.61 & 0.51 \\
\hline $1 \mathrm{DBK}$ & 49 & 0 & 0.47 & 0.41 & 2.40 & 1.73 \\
\hline 1DBM & 66 & 6 & 1.97 & 0.48 & 2.69 & 2.22 \\
\hline 1DDS & 53 & 10 & 1.91 & 1.91 & 2.20 & 0.85 \\
\hline $1 \mathrm{DHF}$ & 49 & 10 & 6.48 & 3.58 & 2.34 & 1.04 \\
\hline 1DID & 25 & 2 & 3.82 & 1.19 & 2.09 & 1.41 \\
\hline 1DIE & 25 & 1 & 0.79 & 0.43 & 1.55 & 0.79 \\
\hline $1 \mathrm{DIH}$ & 74 & 13 & 4.17 & 2.53 & 3.03 & 2.36 \\
\hline 1DM2 & 29 & 0 & 0.67 & 0.52 & 2.05 & 1.54 \\
\hline 1DOG & 25 & 1 & 3.74 & 0.28 & 1.61 & 1.45 \\
\hline 1DR1 & 28 & 2 & 1.47 & 0.18 & 2.36 & 1.72 \\
\hline 1DWB & 18 & 1 & 0.25 & 0.23 & 2.26 & 1.73 \\
\hline 1E5I & 14 & 4 & 0.19 & 0.16 & 1.15 & 1.11 \\
\hline
\end{tabular}

\begin{tabular}{|c|c|c|c|c|c|c|}
\hline \multirow[b]{2}{*}{ PDB ID } & \multirow[b]{2}{*}{$\begin{array}{l}\text { ligand } \\
\text { atoms }\end{array}$} & \multirow[b]{2}{*}{$\begin{array}{c}\text { rot. } \\
\text { bonds }\end{array}$} & \multicolumn{2}{|c|}{ Glide } & \multicolumn{2}{|c|}{ PMFF } \\
\hline & & & $\begin{array}{l}\text { top- } \\
\text { ranked } \\
\text { pose }\end{array}$ & $\begin{array}{l}\text { closest } \\
\text { pose }\end{array}$ & $\begin{array}{l}\text { top- } \\
\text { ranked } \\
\text { pose }\end{array}$ & $\begin{array}{l}\text { closest } \\
\text { pose }\end{array}$ \\
\hline 1EAP & 43 & 11 & 2.32 & 0.63 & 2.69 & 2.12 \\
\hline $1 \mathrm{EJN}$ & 53 & 6 & 0.70 & 0.70 & 3.32 & 2.37 \\
\hline 1ELA & 64 & 13 & 1.60 & 0.97 & 2.24 & 1.76 \\
\hline 1ELB & 69 & 16 & 4.40 & 1.42 & 2.22 & 1.97 \\
\hline 1ELC & 70 & 16 & 8.22 & 4.36 & 2.64 & 2.54 \\
\hline 1ELD & 52 & 12 & 4.40 & 1.42 & 2.89 & 2.12 \\
\hline 1ELE & 48 & 11 & 2.52 & 1.97 & 2.52 & 2.41 \\
\hline 1EPB & 49 & 5 & 1.78 & 0.60 & 0.87 & 0.85 \\
\hline $1 \mathrm{EZQ}$ & 66 & 11 & 1.66 & 1.10 & 3.07 & 1.81 \\
\hline 1F0U & 66 & 11 & 1.59 & 1.16 & 3.12 & 3.12 \\
\hline 1 FEN & 50 & 4 & 0.66 & 0.66 & 1.35 & 1.05 \\
\hline 1FH8 & 37 & 2 & 0.15 & 0.15 & 2.52 & 0.92 \\
\hline 1FHD & 39 & 2 & 6.28 & 1.73 & 2.52 & 1.50 \\
\hline 1FJS & 60 & 9 & 8.49 & 2.62 & 2.82 & 2.54 \\
\hline 1FKG & 68 & 11 & 1.25 & 1.07 & 2.97 & 2.58 \\
\hline $1 \mathrm{FKI}$ & 70 & 0 & 1.92 & 1.48 & 2.55 & 1.16 \\
\hline 1FRP & 30 & 6 & 0.27 & 0.27 & 2.44 & 1.37 \\
\hline $1 \mathrm{GHB}$ & 31 & 7 & 1.89 & 0.64 & 2.16 & 1.80 \\
\hline 1GLQ & 51 & 15 & 0.29 & 0.29 & 2.72 & 1.13 \\
\hline $1 \mathrm{HBV}$ & 95 & 17 & 3.05 & 3.05 & 3.17 & 0.79 \\
\hline $1 \mathrm{HDC}$ & 89 & 6 & 0.58 & 0.37 & 1.64 & 1.43 \\
\hline 1HGG & 81 & 12 & 2.10 & 0.64 & 1.13 & 1.12 \\
\hline $1 \mathrm{HGH}$ & 42 & 7 & 0.28 & 0.28 & 1.82 & 1.16 \\
\hline 1HGI & 47 & 9 & 0.28 & 0.28 & 2.48 & 1.55 \\
\hline 1HGJ & 44 & 7 & 0.18 & 0.16 & 2.11 & 1.79 \\
\hline $1 \mathrm{HIH}$ & 92 & 19 & 1.34 & 1.28 & 2.98 & 1.23 \\
\hline 1HPS & 93 & 19 & 11.85 & 2.33 & 0.80 & 0.80 \\
\hline 1HPX & 87 & 18 & 9.82 & 2.54 & 3.08 & 2.11 \\
\hline 1HRI & 42 & 9 & 1.59 & 1.51 & 0.94 & 0.91 \\
\hline 1HSG & 92 & 14 & 0.32 & 0.30 & 3.18 & 3.15 \\
\hline $1 \mathrm{HSL}$ & 20 & 3 & 1.31 & 0.28 & 2.06 & 1.05 \\
\hline $1 \mathrm{HTF}$ & 79 & 15 & 2.99 & 2.02 & 2.30 & 2.01 \\
\hline 1HTI & 14 & 3 & 4.40 & 0.38 & 1.88 & 1.55 \\
\hline $1 \mathrm{HVR}$ & 84 & 8 & 1.50 & 0.83 & 0.66 & 0.66 \\
\hline $1 \mathrm{HYT}$ & 25 & 5 & 0.28 & 0.28 & 2.26 & 0.91 \\
\hline 1IDA & 104 & 18 & 11.88 & 0.82 & 3.25 & 1.03 \\
\hline 1IGJ & 81 & 3 & 1.30 & 0.67 & 2.84 & 2.62 \\
\hline IIMB & 27 & 2 & 0.89 & 0.73 & 2.47 & 1.99 \\
\hline 1IVB & 25 & 4 & 4.97 & 0.45 & 2.27 & 1.90 \\
\hline 1IVC & 24 & 3 & 1.94 & 1.52 & 2.29 & 1.69 \\
\hline IIVD & 24 & 4 & 0.72 & 0.66 & 1.98 & 1.33 \\
\hline 1IVE & 24 & 3 & 2.61 & 0.89 & 2.24 & 2.02 \\
\hline 1IVF & 36 & 6 & 0.53 & 0.50 & 2.40 & 1.45 \\
\hline $1 \mathrm{LAH}$ & 22 & 4 & 0.13 & 0.13 & 1.97 & 1.30 \\
\hline 1LCP & 23 & 3 & 1.98 & 1.48 & 1.72 & 1.26 \\
\hline $1 \mathrm{LDM}$ & 8 & 1 & 0.30 & 0.30 & 1.65 & 1.43 \\
\hline $1 \mathrm{LMO}$ & 57 & 8 & 0.93 & 0.42 & 2.74 & 2.12 \\
\hline 1LNA & 41 & 9 & 0.95 & 0.70 & 2.49 & 1.61 \\
\hline 1LST & 25 & 5 & 0.14 & 0.14 & 2.10 & 1.05 \\
\hline $1 \mathrm{MBI}$ & 9 & 0 & 1.68 & 0.22 & 1.92 & 1.85 \\
\hline $1 \mathrm{MCR}$ & 38 & 7 & 4.33 & 2.26 & 1.79 & 1.18 \\
\hline $1 \mathrm{MDR}$ & 21 & 2 & 0.52 & 0.46 & 1.61 & 1.33 \\
\hline 1MFE & 64 & 6 & 6.22 & 0.77 & 2.25 & 0.59 \\
\hline $1 \mathrm{MLD}$ & 18 & 5 & 0.32 & 0.15 & 1.73 & 1.36 \\
\hline $1 \mathrm{MRG}$ & 15 & 0 & 0.30 & 0.22 & 2.04 & 1.78 \\
\hline $1 \mathrm{MRK}$ & 32 & 2 & 1.20 & 0.58 & 2.25 & 1.71 \\
\hline $1 \mathrm{MUP}$ & 22 & 2 & 4.37 & 1.99 & 1.28 & 1.04 \\
\hline $1 \mathrm{NIS}$ & 18 & 5 & 0.97 & 0.94 & 2.06 & 0.83 \\
\hline
\end{tabular}


Table 10. continued

\begin{tabular}{|c|c|c|c|c|c|c|}
\hline \multirow[b]{2}{*}{ PDB ID } & \multirow[b]{2}{*}{$\begin{array}{l}\text { ligand } \\
\text { atoms }\end{array}$} & \multirow[b]{2}{*}{$\begin{array}{l}\text { rot. } \\
\text { bonds }\end{array}$} & \multicolumn{2}{|c|}{ Glide } & \multicolumn{2}{|c|}{ PMFF } \\
\hline & & & $\begin{array}{l}\text { top- } \\
\text { ranked } \\
\text { pose }\end{array}$ & $\begin{array}{c}\text { closest } \\
\text { pose }\end{array}$ & $\begin{array}{l}\text { top- } \\
\text { ranked } \\
\text { pose }\end{array}$ & $\begin{array}{c}\text { closest } \\
\text { pose }\end{array}$ \\
\hline $1 \mathrm{NNB}$ & 36 & 6 & 0.55 & 0.25 & 2.17 & 1.34 \\
\hline 1NSC & 39 & 6 & 1.21 & 1.19 & 2.56 & 1.58 \\
\hline $1 \mathrm{NSD}$ & 36 & 6 & 0.27 & 0.22 & 2.49 & 1.58 \\
\hline 1ODW & 84 & 20 & 2.81 & 1.04 & 2.98 & 0.85 \\
\hline $1 P B D$ & 16 & 1 & 0.21 & 0.15 & 2.04 & 1.64 \\
\hline 1PGP & 27 & 7 & 1.88 & 1.20 & 2.04 & 2.04 \\
\hline 1PHA & 44 & 8 & 0.69 & 0.60 & 2.02 & 1.59 \\
\hline $1 \mathrm{PHD}$ & 19 & 1 & 1.22 & 0.85 & 2.03 & 0.99 \\
\hline $1 \mathrm{PHF}$ & 19 & 1 & 1.14 & 0.56 & 2.16 & 1.33 \\
\hline $1 \mathrm{PHG}$ & 31 & 3 & 4.32 & 1.42 & 2.07 & 1.47 \\
\hline $1 \mathrm{PPI}$ & 111 & 12 & 6.24 & 1.97 & 3.20 & 1.63 \\
\hline $1 \mathrm{PPK}$ & 80 & 19 & 0.45 & 0.41 & 3.04 & 2.76 \\
\hline $1 P P L$ & 91 & 21 & 2.82 & 1.95 & 3.42 & 0.72 \\
\hline $1 \mathrm{PPM}$ & 81 & 20 & 0.62 & 0.62 & 3.44 & 3.33 \\
\hline 1PRO & 80 & 10 & 1.46 & 1.46 & 0.89 & 0.89 \\
\hline $1 \mathrm{RBP}$ & 51 & 5 & 0.96 & 0.87 & 1.30 & 1.30 \\
\hline $1 \mathrm{RDS}$ & 63 & 8 & 3.75 & 0.82 & 0.60 & 0.60 \\
\hline $1 \mathrm{RHL}$ & 37 & 4 & 0.93 & 0.42 & 1.92 & 1.50 \\
\hline 1RLS & 37 & 4 & 2.69 & 0.51 & 2.40 & 1.40 \\
\hline $1 \mathrm{RNE}$ & 114 & 24 & 10.08 & 3.51 & 1.25 & 1.04 \\
\hline $1 \mathrm{RNT}$ & 36 & 4 & 0.72 & 0.53 & 2.43 & 2.05 \\
\hline $1 \mathrm{ROB}$ & 33 & 4 & 1.85 & 1.12 & 1.99 & 1.83 \\
\hline $1 \mathrm{SBG}$ & 81 & 16 & 0.74 & 0.67 & 1.09 & 0.95 \\
\hline 1SLT & 51 & 6 & 0.51 & 0.24 & 1.10 & 1.10 \\
\hline $1 S N C$ & 37 & 6 & 1.91 & 0.97 & 2.63 & 2.17 \\
\hline 1STP & 31 & 5 & 0.59 & 0.33 & 2.39 & 1.79 \\
\hline $1 \mathrm{TDB}$ & 33 & 4 & 1.46 & 0.99 & 2.62 & 1.50 \\
\hline $1 \mathrm{THY}$ & 32 & 4 & 2.31 & 1.65 & 2.54 & 1.38 \\
\hline $1 \mathrm{TMN}$ & 67 & 14 & 2.80 & 0.81 & 2.75 & 2.56 \\
\hline $1 T N G$ & 24 & 1 & 0.19 & 0.09 & 0.91 & 0.91 \\
\hline $1 \mathrm{TNH}$ & 18 & 1 & 0.33 & 0.12 & 1.91 & 1.49 \\
\hline $1 \mathrm{TNI}$ & 27 & 4 & 2.18 & 0.59 & 1.60 & 1.17 \\
\hline $1 \mathrm{TNJ}$ & 21 & 2 & 0.35 & 0.24 & 1.99 & 1.28 \\
\hline $1 T N K$ & 24 & 3 & 0.87 & 0.69 & 1.71 & 0.91 \\
\hline $1 T N L$ & 22 & 1 & 0.23 & 0.11 & 1.85 & 1.16 \\
\hline $1 \mathrm{TPP}$ & 27 & 4 & 1.12 & 0.39 & 2.25 & 2.01 \\
\hline $1 \mathrm{TYL}$ & 20 & 2 & 1.06 & 0.41 & 1.66 & 1.14 \\
\hline $1 \mathrm{UKZ}$ & 35 & 4 & 0.37 & 0.35 & 2.36 & 1.21 \\
\hline $1 \mathrm{ULB}$ & 16 & 0 & 0.28 & 0.25 & 2.11 & 1.34 \\
\hline 1WAP & 27 & 3 & 0.12 & 0.06 & 2.03 & 1.33 \\
\hline 1XID & 20 & 2 & 4.30 & 1.14 & 2.00 & 1.87 \\
\hline 1XIE & 23 & 1 & 3.86 & 0.22 & 1.91 & 1.00 \\
\hline $2 \mathrm{ADA}$ & 33 & 2 & 0.53 & 0.37 & 2.34 & 2.10 \\
\hline $2 \mathrm{AK} 3$ & 35 & 4 & 0.71 & 0.70 & 2.73 & 1.41 \\
\hline 2CGR & 49 & 8 & 0.38 & 0.35 & 3.00 & 2.15 \\
\hline $2 \mathrm{CHT}$ & 28 & 2 & 0.42 & 0.19 & 2.00 & 1.54 \\
\hline $2 \mathrm{CMD}$ & 18 & 5 & 0.65 & 0.27 & 2.06 & 1.67 \\
\hline $2 \mathrm{CPP}$ & 27 & 0 & 0.17 & 0.09 & 1.73 & 0.97 \\
\hline 2CTC & 21 & 3 & 1.61 & 0.48 & 1.22 & 0.80 \\
\hline $2 \mathrm{DBL}$ & 67 & 6 & 0.69 & 0.67 & 2.91 & 1.63 \\
\hline $2 \mathrm{GBP}$ & 24 & 1 & 0.15 & 0.11 & 1.02 & 0.79 \\
\hline 2IFB & 49 & 14 & 1.36 & 0.87 & 2.11 & 1.40 \\
\hline
\end{tabular}

standard deviation of the RMSD is related to the generality of the potential energy function. The standard deviation of the RMSD in the PMFF is not only smaller than that of Glide but is also less than 1 A. The results for Glide show 16 PDB complexes

\begin{tabular}{|c|c|c|c|c|c|c|}
\hline \multirow[b]{2}{*}{ PDB ID } & \multirow[b]{2}{*}{$\begin{array}{l}\text { ligand } \\
\text { atoms }\end{array}$} & \multirow[b]{2}{*}{$\begin{array}{c}\text { rot. } \\
\text { bonds }\end{array}$} & \multicolumn{2}{|c|}{ Glide } & \multicolumn{2}{|c|}{ PMFF } \\
\hline & & & $\begin{array}{l}\text { top- } \\
\text { ranked } \\
\text { pose }\end{array}$ & $\begin{array}{l}\text { closest } \\
\text { pose }\end{array}$ & $\begin{array}{l}\text { top- } \\
\text { ranked } \\
\text { pose }\end{array}$ & $\begin{array}{c}\text { closest } \\
\text { pose }\end{array}$ \\
\hline 2LGS & 18 & 4 & 7.55 & 0.33 & 2.34 & 1.82 \\
\hline $2 \mathrm{MCP}$ & 24 & 4 & 1.30 & 0.81 & 1.88 & 1.17 \\
\hline $2 \mathrm{PHH}$ & 15 & 1 & 0.38 & 0.28 & 1.96 & 1.70 \\
\hline $2 \mathrm{PK} 4$ & 22 & 5 & 0.86 & 0.58 & 1.41 & 1.21 \\
\hline $2 \mathrm{PLV}$ & 59 & 15 & 1.88 & 0.77 & 2.59 & 2.59 \\
\hline 2R04 & 51 & 10 & 0.80 & 0.64 & 3.35 & 1.34 \\
\hline 2R07 & 45 & 8 & 0.48 & 0.48 & 2.43 & 2.05 \\
\hline 2SIM & 36 & 6 & 0.92 & 0.30 & 2.28 & 1.66 \\
\hline $2 \mathrm{TPI}$ & 38 & 7 & 0.49 & 0.48 & 1.13 & 1.13 \\
\hline 2UPJ & 81 & 15 & 3.65 & 2.85 & 1.58 & 1.17 \\
\hline 2XIS & 22 & 4 & 0.85 & 0.37 & 2.03 & 1.22 \\
\hline 2YPI & 11 & 3 & 0.31 & 0.20 & 1.98 & 1.42 \\
\hline 3CLA & 32 & 7 & 8.51 & 3.46 & 1.84 & 1.10 \\
\hline $3 \mathrm{CPA}$ & 30 & 6 & 2.40 & 0.66 & 1.01 & 0.77 \\
\hline 3DFR & 53 & 10 & 0.87 & 0.38 & 0.95 & 0.95 \\
\hline 3HVT & 34 & 1 & 0.77 & 0.62 & 1.25 & 1.15 \\
\hline 3MTH & 19 & 2 & 5.48 & 0.21 & 2.28 & 1.71 \\
\hline ЗРТВ & 18 & 1 & 0.27 & 0.20 & 1.91 & 1.78 \\
\hline 3TPI & 38 & 7 & 0.49 & 0.23 & 1.83 & 1.54 \\
\hline 4AAH & 27 & 3 & 0.30 & 0.14 & 2.19 & 1.34 \\
\hline 4CTS & 11 & 3 & 0.44 & 0.19 & 2.18 & 1.71 \\
\hline 4DFR & 53 & 10 & 1.12 & 0.92 & 2.09 & 1.04 \\
\hline $4 \mathrm{FAB}$ & 35 & 2 & 4.50 & 0.69 & 2.20 & 1.97 \\
\hline $4 \mathrm{FBP}$ & 35 & 4 & 0.56 & 0.56 & 2.51 & 1.90 \\
\hline $4 \mathrm{FXN}$ & 50 & 7 & 0.44 & 0.44 & 2.41 & 1.04 \\
\hline $4 \mathrm{HMG}$ & 39 & 6 & 0.78 & 0.72 & 1.86 & 1.80 \\
\hline $4 \mathrm{PHV}$ & 88 & 14 & 0.38 & 0.38 & 0.79 & 0.65 \\
\hline 4TIM & 16 & 4 & 1.32 & 0.97 & 2.03 & 1.25 \\
\hline 4TPI & 35 & 6 & 0.51 & 0.23 & 1.99 & 0.92 \\
\hline $4 \mathrm{TS} 1$ & 24 & 3 & 0.85 & 0.57 & 2.56 & 1.85 \\
\hline $5 \mathrm{ABP}$ & 24 & 1 & 0.21 & 0.10 & 1.51 & 1.41 \\
\hline $5 \mathrm{CPP}$ & 25 & 0 & 0.59 & 0.10 & 1.55 & 1.21 \\
\hline 5CTS & 11 & 3 & 0.28 & 0.17 & 1.62 & 1.18 \\
\hline $5 \mathrm{P} 2 \mathrm{P}$ & 69 & 21 & 1.82 & 1.34 & 3.10 & 2.53 \\
\hline $6 \mathrm{ABP}$ & 20 & 0 & 0.40 & 0.14 & 1.99 & 1.06 \\
\hline $6 \mathrm{CPA}$ & 58 & 14 & 4.58 & 1.37 & 2.90 & 2.77 \\
\hline 6RNT & 35 & 4 & 2.22 & 2.22 & 2.69 & 1.84 \\
\hline 6TIM & 17 & 4 & 1.73 & 0.25 & 2.28 & 2.02 \\
\hline $6 \mathrm{TMN}$ & 63 & 16 & 2.66 & 1.26 & 2.95 & 2.75 \\
\hline $7 \mathrm{ABP}$ & 23 & 0 & 0.20 & 0.06 & 0.83 & 0.83 \\
\hline $7 \mathrm{CPA}$ & 74 & 17 & 4.14 & 2.41 & 2.99 & 2.64 \\
\hline 7СРP & 18 & 0 & 0.61 & 0.61 & 1.69 & 0.96 \\
\hline $8 \mathrm{ABP}$ & 24 & 1 & 0.22 & 0.13 & 1.00 & 1.00 \\
\hline 8ATC & 23 & 7 & 0.37 & 0.34 & 2.17 & 1.70 \\
\hline $8 \mathrm{GCH}$ & 44 & 9 & 0.30 & 0.30 & 2.16 & 1.77 \\
\hline $9 \mathrm{ABP}$ & 24 & 1 & 0.15 & 0.13 & 1.37 & 1.31 \\
\hline average & & & 1.86 & 0.82 & 2.12 & 1.52 \\
\hline standard & ation & & 2.31 & 0.79 & 0.67 & 0.58 \\
\hline
\end{tabular}

${ }^{a}$ Top-ranked pose was determined by minimum intermolecular potential energy. The closest pose was determined by minimum RMSD. with the RMSD for a top-ranked binding pose of greater than 5 A. According to these results, if an accurate binding pose can be generated in a binding pose search algorithm, the calculated binding poses are accurately evaluated by the scoring function 
used in the PMFF and have greater reliability. Therefore, the PMFF can be expressed well in a biological system.

A comparison of computation time between Glide and our algorithm is shown in Table S1. The calculation time for our algorithm is longer than the calculation time for Glide because our algorithm was dependent on the number of conformers of ligand. If the algorithm of determination of the 4rotatable bond is more efficient, such as not including hydrogen in methyl group, calculation time will be reduced.

3.3. Verification of the Combination between PMFF and GSFED Models. To confirm the suitability of the combination of the PMFF and GSFED models, ${ }^{50}$ preliminary studies using the water-octanol partition coefficients of various peptide lengths and 193 natural peptides were performed to calculate and compare with the experiment data. The structures of the peptides were calculated using the PMFF, and the majority of parameters used in GSFED, shown in eq 13a, are from the PMFF. The mean absolute error and root-mean-square error for neutral peptides were $1.615 \mathrm{log}$ units and 2.140 in SM5.42R and $0.322 \mathrm{log}$ units and 1.468 in GSFED. Therefore, the combination between PMFF and GSFED models is well described for a biological system.

\section{CONCLUSIONS}

This paper describes a continuous 25 year effort to develop a force field for the simulation of protein and biological molecules. The force field is the result of tremendous effort of many different people and a long period of time. As the term physicsbased molecular force field suggests, the force field is well balanced for representing inter- and intra-interactions as well as the solvation effect. The performance of the PMFF was validated by comparing the difference in conformer energy, applying a docking simulation on 214 PDB complexes, and calculating the octanol-water partition coefficient for neutral peptides. The test results prove that the PMFF predicts the molecular structure more reliably and interprets the biological phenomena extremely accurately. It is therefore suitable for describing biological phenomena.

A PMFF-based graphic user interface program for molecular structure optimization, a single-point energy calculation, solvation-free energy calculation, and molecular docking simulation is available on GitHub (github.com/PMFF/GUI).

\section{ASSOCIATED CONTENT}

\section{SI Supporting Information}

The Supporting Information is available free of charge at https://pubs.acs.org/doi/10.1021/acs.jpcb.9b10339.

Calculation time of molecular docking simulation for five protein-ligand complexes using Glide and PMFF; distribution of the 133 organic molecules in the principle component space; and conformer energy difference (kcal/mol) calculated with DFT B3LYP/6-31G**, MM3, and PMFF (PDF)

\section{AUTHOR INFORMATION}

\section{Corresponding Author}

Kyoung Tai No - Department of Biotechnology, Yonsei University, Seoul KR 120-479, Republic of Korea; Bioinformatics \& Molecular Design Research Center, Seoul KR 120-479, Republic of Korea; (이이.org/0000-0003-3187-8193; Phone: +82-2-393-9550; Email: ktno@yonsei.ac.kr; Fax: +82-2-393-9554

\section{Authors}

Sung Bo Hwang - Department of Biotechnology, Yonsei University, Seoul KR 120-479, Republic of Korea; 이이이.org/ 0000-0002-1610-5259

Chang Joon Lee - Dotmatic, Suwon 16226, Republic of Korea Sehan Lee - Molecular Design Team, New Drug Development Center, Daegu- Gyeongbuk Medical Innovation Foundation (DGMIF), 41061 Daegu City, Republic of Korea

Songling Ma - Xtalpi-AI Research Center, Xtalpi Inc., Bejing, China 100090

Young-Mook Kang - Korea Research Institute of Chemical Technology, Drug Information Platform Center, Daejon 34114, Republic of Korea; (c) orcid.org/0000-0002-0413-4933

Kwang Hwi Cho - Department of Bioinformatics, Soongsil University, Seoul 156-743, Republic of Korea

Su-Yeon Kim - School of Liberal Arts Education (Chemistry), College of Liberal Arts and Cross-Disciplinary Studies, University of Seoul, Seoul 02504, Republic of Korea

Oh Young Kwon - Wooreebio Institute, Ansan-si 15409, Republic of Korea

Chang No Yoon - Department of Neuroscience, Korea University of Science and Technology, Seoul 02792, Republic of Korea

Young Kee Kang - Department of Chemistry, Chungbuk National University, Cheongiu 28644, Republic of Korea; (1) orcid.org/0000-0002-2200-8922

Jeong Hyeok Yoon - Research Center, Pharos I\&BT Co., Ltd., Anyang 14059, Republic of Korea

Ky-Youb Nam - Research Center, Pharos I\&BT Co., Ltd., Anyang 14059, Republic of Korea

Seong-Gon Kim - Korea Biopharm Co., LTD., Seongnam-si 13631, Republic of Korea

Youngyong In - Vovi C\&E Co. Ltd., Seoul 06724, Republic of Korea

Han Ha Chai - National institute of animal science, Wanju-gun 55365, Republic of Korea

William E. Acree, Jr. - Department of Chemistry, University of North Texas, Denton, Texas 76230-5017, United States; (1) orcid.org/0000-0002-1177-7419

J. Andrew Grant - Baker Laboratory of Chemistry and Chemical Biology, Cornell University, Ithaca, New York 14853-1301, United States

Ken D. Gibson - Baker Laboratory of Chemistry and Chemical Biology, Cornell University, Ithaca, New York 14853-1301, United States

Mu Shik Jhon - Baker Laboratory of Chemistry and Chemical Biology, Cornell University, Ithaca, New York 14853-1301, United States

Harold A. Scheraga - Baker Laboratory of Chemistry and Chemical Biology, Cornell University, Ithaca, New York 148531301, United States; (1) orcid.org/0000-0002-6314-5376

Complete contact information is available at:

https://pubs.acs.org/10.1021/acs.jpcb.9b10339

\section{Notes}

The authors declare no competing financial interest.

\section{ACKNOWLEDGMENTS}

This study was supported by BMDRC. K.T.N. thanks H.A.S. for waiting 25 years for this study. We thank Late Dr. Mu Shik Jhon for many helpful discussions. H.A.S. thanks the National Institutes of Health (GM-14312) for the support. 


\section{REFERENCES}

(1) Momany, F. A.; McGuire, R. F.; Burgess, A. W.; Scheraga, H. A. Energy parameters in polypeptides. VII. Geometric parameters, partial atomic charges, nonbonded interactions, hydrogen bond interactions, and intrinsic torsional potentials for the naturally occurring amino acids. J. Phys. Chem. 1975, 79, 2361-2381.

(2) Nemethy, G.; Pottle, M. S.; Scheraga, H. A. Energy parameters in polypeptides. 9. Updating of geometrical parameters, nonbonded interactions, and hydrogen bond interactions for the naturally occurring amino acids. J. Phys. Chem. 1983, 87, 1883-1887.

(3) Sippl, M. J.; Nemethy, G.; Scheraga, H. A. Intermolecular potentials from crystal data. 6 . Determination of empirical potentials for $\mathrm{O}-\mathrm{H} . . . \mathrm{O}=\mathrm{C}$ hydrogen bonds from packing configurations. J. Phys. Chem. 1984, 88, 6231-6233.

(4) Nemethy, G.; Gibson, K. D.; Palmer, K. A.; Yoon, C. N.; Paterlini, G.; Zagari, A.; Rumsey, S.; Scheraga, H. A. Energy parameters in polypeptides. 10. Improved geometrical parameters and nonbonded interactions for use in the ECEPP/3 algorithm, with application to proline-containing peptides. J. Phys. Chem. 1992, 96, 6472-6484.

(5) Arnautova, Y. A.; Jagielska, A.; Scheraga, H. A. A New Force Field (ECEPP-05) for peptides, Proteins, and Organic Molecules. J. Phys. Chem. B 2006, 110, 5025-5044.

(6) Allinger, N. L.; Yuh, Y. H.; Lii, J. H. Molecular mechanics. The MM3 force field for hydrocarbons. 1. J. Am. Chem. Soc. 1989, 111, $8551-8566$.

(7) Lii, J. H.; Allinger, N. L. Molecular mechanics. The MM3 force field for hydrocarbons. 2. Vibrational frequencies and thermodynamics. J. Am. Chem. Soc. 1989, 111, 8566-8575.

(8) Lii, J. H.; Allinger, N. L. Molecular mechanics. The MM3 force field for hydrocarbons. 3 . The van der Waals' potentials and crystal data for aliphatic and aromatic hydrocarbons. J. Am. Chem. Soc. 1989, 111, $8576-8582$.

(9) Brooks, B. R.; Bruccoleri, R. E.; Olafson, B. D.; States, D. J.; Swaminathan, S.; Karplus, M. CHARMM: A program for macromolecular energy, minimization, and dynamics calculations. J. Comput. Chem. 1983, 4, 187-217.

(10) Vanommeslaeghe, K.; Hatcher, E.; Acharya, C.; Kundu, S.; Zhong, S.; Shim, J.; Darian, E.; Guvench, O.; Lopes, P.; Vorobyov, I.; Mackerell, A. D., Jr. CHARMM general force field: A force field for drug-like molecules compatible with the CHARMM all-atom additive biological force fields. J. Comput. Chem. 2010, 31, 671-690.

(11) Brooks, B. R.; Brooks, C. L., III; Mackerell, A. D., Jr.; Nilsson, L.; Petrella, R. J.; Roux, B.; Won, Y.; Archontis, G.; Bartels, C.; Boresch, S.; Caflisch, A.; Caves, L.; Cui, Q.; Dinner, A. R.; Feig, M.; Fischer, S.; Gao, J.; Hodoscek, M.; Im, W.; Kuczera, K.; Lazaridis, T.; Ma, J.; Ovchinnikov, V.; Paci, E.; Pastor, R. W.; Post, C. B.; Pu, J. Z.; Schaefer, M.; Tidor, B.; Venable, R. M.; Woodcock, H. L.; Wu, X.; Yang, W.; York, D. M.; Karplus, M. CHARMM: The biomolecular simulation program. J. Comput. Chem. 2009, 30, 1545-1614.

(12) Pastor, R. W.; MacKerell, A. D., Jr. Development of the CHARMM Force Field for Lipids. J. Phys. Chem. Lett. 2011, 2, 15261532.

(13) Vanommeslaeghe, K.; MacKerell, A. D., Jr. Automation of the CHARMM General Force Field (CGenFF) I: Bond Perception and Atom Typing. J. Chem. Inf. Model. 2012, 52, 3144-3154.

(14) Vanommeslaeghe, K.; Raman, E. P.; MacKerell, A. D., Jr. Automation of the CHARMM General Force Field (CGenFF) II: Assignment of Bonded Parameters and Partial Atomic Charges. J. Chem. Inf. Model. 2012, 52, 3155-3168.

(15) Patel, S.; Brooks, C. L., III CHARMM fluctuating charge force field for proteins: I parameterization and application to bulk organic liquid simulations. J. Comput. Chem. 2004, 25, 1-16.

(16) Patel, S.; Mackerell, A. D., Jr.; Brooks, C. L., III CHARMM

fluctuating charge force field for proteins: II Protein/solvent properties from molecular dynamics simulations using a nonadditive electrostatic model. J. Comput. Chem. 2004, 25, 1504-1514.

(17) Guvench, O.; Hatcher, E.; Venable, R. M.; Pastor, R. W.; MacKerell, A. D., Jr. CHARMM Additive All-Atom Force Field for
Glycosidic Linkages between Hexopyranoses. J. Chem. Theory Comput. 2009, 5, 2353-2370.

(18) Weiner, S. J.; Kollman, P. A.; Case, D. A.; Singh, U. C.; Ghio, C.; Alagona, G.; Profeta, S.; Weiner, P. A new force field for molecular mechanical simulation of nucleic acids and proteins. J. Am. Chem. Soc. 1984, 106, 765-784.

(19) Cornell, W. D.; Cieplak, P.; Bayly, C. I.; Gould, I. R.; Merz, K. M.; Ferguson, D. M.; Spellmeyer, D. C.; Fox, T.; Caldwell, J. W.; Kollman, P. A. A Second Generation Force Field for the Simulation of Proteins, Nucleic Acids, and Organic Molecules. J. Am. Chem. Soc. 1995, 117, 5179-5197.

(20) Wang, J.; Wolf, R. M.; Caldwell, J. W.; Kollman, P. A.; Case, D. A. Development and testing of a general amber force field. J. Comput. Chem. 2004, 25, 1157-1174.

(21) Homeyer, N.; Horn, A. H. C.; Lanig, H.; Sticht, H. AMBER force-field parameters for phosphorylated amino acids in different protonation states: phosphoserine, phosphothreonine, phosphotyrosine, and phosphohistidine. J. Mol. Model. 2006, 12, 281-289.

(22) Peters, M. B.; Yang, Y.; Wang, B.; Füsti-Molnár, L.; Weaver, M. N.; Merz, K. M., Jr. Structural Survey of Zinc-Containing Proteins and Development of the Zinc AMBER Force Field (ZAFF). J. Chem. Theory Comput. 2010, 6, 2935-2947.

(23) Dickson, C. J.; Rosso, L.; Betz, R. M.; Walker, R. C.; Gould, I. R. GAFFlipid: a General Amber Force Field for the accurate molecular dynamics simulation of phospholipid. Soft Matter 2012, 8, 9617-9627.

(24) Halgren, T. A. Merck molecular force field. I. Basis, form, scope, parameterization, and performance of MMFF94. J. Comput. Chem. 1996, 17, 490-519.

(25) Halgren, T. A. Merck molecular force field. II. MMFF94 van der Waals and electrostatic parameters for intermolecular interactions. $J$. Comput. Chem. 1996, 17, 520-552.

(26) Halgren, T. A. Merck molecular force field. III. Molecular geometries and vibrational frequencies for MMFF94. J. Comput. Chem. 1996, 17, 553-586.

(27) Halgren, T. A.; Nachbar, R. B. Merck molecular force field. IV. conformational energies and geometries for MMFF94. J. Comput. Chem. 1996, 17, 587-615.

(28) Halgren, T. A. Merck molecular force field. V. Extension of MMFF94 using experimental data, additional computational data, and empirical rules. J. Comput. Chem. 1996, 17, 616-641.

(29) Maple, J. R.; Dinur, U.; Hagler, A. T. Derivation of force fields for molecular mechanics and dynamics from ab initio energy surfaces. Proceedings of the National Academy of Sciences 1988, 85, 5350-5354.

(30) Jorgensen, W. L.; Tirado-Rives, J. The OPLS [optimized potentials for liquid simulations] Potential Functions for Proteins. Energy Minimizations for Crystals of Cyclic Peptides and Crambin. J. Am Chem. Soc. 1988, 110, 1657-1666.

(31) Harder, E.; Damm, W.; Maple, J.; Wu, C.; Reboul, M.; Xiang, J. Y.; Wang, L.; Lupyan, D.; Dahlgren, M. K.; Knight, J. L.; Kaus, J. W.; Cerutti, D. S.; Krilov, G.; Jorgensen, W. L.; Abel, R.; Friesner, R. A. OPLS3: A Force Field Providing Broad Coverage of Drug-like Small Molecules and Proteins. J. Chem. Theory Comput. 2015, 12, 281-296.

(32) Damm, W.; Frontera, A.; Tirado-Rives, J.; Jorgensen, W. L. OPLS all-atom force field for carbohydrates. J. Comput. Chem. 1997, 18, 1955-1970.

(33) Hagler, A. T.; Huler, E.; Lifson, S. Energy functions for peptides and proteins. I. Derivation of a consistent force field including the hydrogen bond from amide crystals. J. Am. Chem. Soc. 1974, 96, 53195327.

(34) Hagler, A. T.; Lifson, S. Energy functions for peptides and proteins. II. Amide hydrogen bond and calculation of amide crystal properties. J. Am. Chem. Soc. 1974, 96, 5327-5335.

(35) Jorgensen, W. L. Transferable Intermolecular Potential Functions for Water, Alcohols, and Ethers. Application to Liquid Water. J. Am. Chem. Soc. 1981, 103, 335-340.

(36) Klamt, A. Conductor-like Screening Model for Real Solvents: A New Approach to the Quantitative Calculation of Solvation Phenomena. J. Phys. Chem. 1995, 99, 2224-2235. 
(37) Klamt, A.; Schüürmann, G. COSMO: a new approach to dielectric screening in solvents with explicit expressions for the screening energy and its gradient. J. Chem. Soc., Perkin Trans. 2 1993, 2, 799-805.

(38) Giesen, D. J.; Gu, M. Z.; Cramer, C. J.; Truhlar, D. G. A Universal Organic Solvation Model. J. Org. Chem. 2000, 65, 5886-5886.

(39) Li, J.; Zhu, T.; Hawkins, G. D.; Winget, P.; Liotard, D. A.; Cramer, C. J.; Truhlar, D. G. Extension of the platform of applicability of the SM5.42R universal solvation model. Theor. Chem. Acc. 1999, 103, $9-63$.

(40) Cramer, C. J.; Truhlar, D. G. A Universal Approach to Solvation Modeling. Acc. Chem. Res. 2008, 41, 760-768.

(41) No, K. T.; Grant, J. A.; Scheraga, H. A. Determination of net atomic charges using a modified partial equalization of orbital electronegativity method. 1. Application to neutral molecules as models for polypeptides. J. Phys. Chem. 1990, 94, 4732-4739.

(42) No, K. T.; Grant, J. A.; Jhon, M. S.; Scheraga, H. A. Determination of net atomic charges using a modified partial equalization of orbital electronegativity method. 2. Application to ionic and aromatic molecules as models for polypeptides. J. Phys. Chem. 1990, 94, 4740-4746.

(43) Park, J. M.; No, K. T.; Jhon, M. S.; Scheraga, H. A. Determination of net atomic charges using a modified partial equalization of orbital electronegativity method III: application to halogenated and aromatic molecules. J. Comput. Chem. 1993, 14, 1482-1490.

(44) Park, J. M.; Kwon, O. Y.; No, K. T.; Jhon, M. S.; Scheraga, H. A. Determination of net atomic charges using a modified partial equalization of orbital electronegativity method IV. Application to hypervalent sulfur- and phosphorus-containing molecules. J. Comput. Chem. 1995, 16, 1011-1026.

(45) Suk, J. E.; No, K. T. Determination of net atomic charges using a modified partial equalization of orbital electronegativity method V. Application to silicon-containing organic molecules and zeolites. Bull. Korean Chem. Soc. 1995, 16, 915-923.

(46) Scott, R. A.; Scheraga, H. A. Conformational Analysis of Macromolecules. III. Helical Structures of Polyglycine and Poly-LAlanine. J. Chem. Phys. 1966, 45, 2091-2101.

(47) No, K. T.; Cho, K. H.; Jhon, M. S.; Scheraga, H. A. An empirical method to calculate average molecular polarizabilities from the dependence of effective atomic polarizabilities on net atomic charge. J. Am. Chem. Soc. 1993, 115, 2005-2014.

(48) No, K. T.; Kwon, O. Y.; Kim, S. Y.; Cho, K. H.; Yoon, C. N.; Kang, Y. K.; Gibson, K. D.; Jhon, M. S.; Scheraga, H. A. Determination of Nonbonded Potential Parameters for Peptides. J. Phys. Chem. 1995, 99, 13019-13027.

(49) No, K. T.; Kwon, O. Y.; Kim, S. Y.; Jhon, M. S.; Scheraga, H. A. A Simple Functional Representation of Angular-Dependent HydrogenBonded Systems. 1. Amide, Carboxylic Acid, and Amide-Carboxylic Acid Pairs. J. Phys. Chem. 1995, 99, 3478-3486.

(50) Lee, S.; Cho, K.-H.; Kang, Y.-M.; Scheraga, H. A.; No, K. T. A generalized G-SFED continuum solvation free energy calculation model. Proc. Natl. Acad. Sci. 2013, 110, E662.

(51) Ma, S.; Hwang, S.; Lee, S.; Acree, W. E., Jr.; No, K. T. Incorporation of Hydrogen Bond Angle Dependency into the Generalized Solvation Free Energy Density Model. J. Chem. Inf. Model. 2018, 58, 761-772.

(52) Miller, K. J.; Savchik, J. A new empirical method to calculate average molecular polarizabilities. J. Am. Chem. Soc. 1979, 101, 72067213.

(53) Kang, Y. K.; Jhon, M. S. Additivity of atomic static polarizabilities and dispersion coefficients. Theor. Chim. Acta 1982, 61, 41-48.

(54) Israelachvili, J. In Intermolecular and Surface Forces; Academic Press: New York, 1991; Chapter 11.

(55) Steinbeck, C.; Han, Y.; Kuhn, S.; Horlacher, O.; Luttmann, E.; Willighagen, E. The Chemistry Development Kit (CDK): An opensource Java library for chemo- and bioinformatics. J. Chem. Inf. Comput. Sci. 2003, 43, 493-500.

(56) Schrödinger Release 2018-3: Maestro, Schrödinger, LLC, New York, NY, 2018.
(57) Goldstein, A. A. Cauchy's method of minimization. Numerische Mathematik 1962, 4, 146-150.

(58) Kiefer, J. Sequential minimax search for a maximum. Proc. Am. Math. Soc. 1953, 4, 502-506.

(59) Kim, S.; Thiessen, P. A.; Bolton, E. E.; Chen, J.; Fu, G.; Gindulyte, A.; Han, L.; He, J.; He, S.; Shoemaker, B. A.; Wang, J.; Yu, B.; Zhang, J.; Bryant, S. H. PubChem Substance and Compound databases. Nucleic Acids Res. 2016, 44, D1202-D1213.

(60) Gundertofte, K.; Liljefors, T.; Norrby, P.-o.; Pettersson, I. A comparison of conformational energies calculated by several molecular mechanics methods. J. Comput. Chem. 1996, 17, 429-449.

(61) Berman, H. M.; Westbrook, J.; Feng, Z.; Gilliland, G.; Bhat, T. N.; Weissig, H.; Shindyalov, I. N.; Bourne, P. E. The Protein Data Bank. Nucleic Acids Res. 2000, 28, 235-242.

(62) Daylight 4. SMART-a language for describing molecular patterns. http://www.daylight.com/dayhtml/doc/theory/theory.smarts.html 